\title{
The vorticity and angular momentum budgets of Asian summer monsoon
}

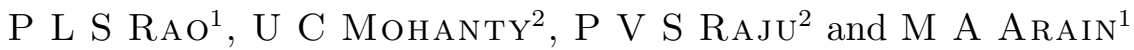 \\ ${ }^{1}$ School of Geography and Geology, McMaster University, Hamilton, ON, Canada L8S 4 K1. \\ ${ }^{2}$ Centre for Atmospheric Sciences, Indian Institute of Technology-Delhi Hauz Khas, New Delhi 110 016, India.
}

The study delineates the vorticity and angular momentum balances of Asian summer monsoon during the evolution and established phases. It also elucidates the differences between these balances in the National Centre for Environmental Prediction/National Centre for Atmospheric Research (NCEP/NCAR) reanalysis and the National Centre for Medium Range Weather Forecasts (NCMRWF) analysis fields. The NCEP/NCAR reanalysis for a 40 year period (1958-97) and the NCMRWF analysis for a three year (1994-96) period are made use of for the purpose. The time mean summer monsoon circulation is bifurcated into stable mean and transient eddy components and the mean component is elucidated.

The generation of vorticity due to stretching of isobars balances most of the vorticity transported out of the monsoon domain during the evolution period. However, during the established period, the transportation by the relative and planetary vorticity components exceeds the generation due to stretching. The effective balancing mechanism is provided by vorticity generation due to sub-grid scale processes. The flux convergence of omega and relative momenta over the monsoon domain is effectively balanced by pressure torque during the evolution and established phases. Nevertheless, the balance is stronger during the established period due to the increase in the strength of circulation.

Both the NCMRWF and NCEP fields indicate the mean features related to vorticity and angular momentum budgets realistically. Apart from the oceanic bias (strong circulation over oceans rather than continents), the summer monsoon circulation indicated by the NCEP is feeble compared to NCMRWF. The significant terms in the large-scale budgets of vorticity and angular momentum enunciate this aspect.

\section{Introduction}

The Asian summer monsoon is a thermally driven circulation, which arises primarily from the temperature differences between the warmer continental areas of the northern hemisphere and the oceans of the southern hemisphere. The complex feedback between the flow field and the heating, especially through the interaction between the large-scale flow and moist convection, is yet to be well understood. Nevertheless, this facet ensures the prominence of the summer monsoon circulation. The peculiar orography of the Indian subcon- tinent also modifies the circulation considerably. The result is that the monsoon in particular is a complex weather system. The life cycle of the Asian summer monsoon commences with an abrupt onset in spring, followed by an active period in June - August producing copious rainfall over Asia, and slowly dies out over autumn. The sequence of events, which culminate in the establishment of monsoon, may be succinctly stated as follows. A zone of high pressure builds up over the Indian Ocean in May, though in some years it is more pronounced than others. From early May onwards a thermal low develops over northwest India and the

Keywords. Summer monsoon; NCEP/NCAR reanalysis; NCMRWF analysis; vorticity and angular momentum budget. 
adjoining parts of Pakistan due to seasonal changes in the insolation. The atmosphere responds to these changes by setting up a trans-equatorial current. This flow transports ample mass and moisture from southern hemisphere to the monsoon domain. More than half of the total low-level transport between the southern and northern hemispheres occurs within the confines of the Somali jet. The inter tropical convergence zone (ITCZ) moves northwards from the Indian Ocean in response to the heating pattern over continental India around late May. Despite the annual rainfall being normal, the ill-timed rainfall produces devastating effects. Consequently, the forecasting of monsoons in various time scales (a few days to years ahead) is a crucial issue. The sparse data network over the tropics has made many nuances of the summer monsoon esoteric. However, the First GARP Global Experiment (FGGE) and the abundant availability of data through multifarious operational weather forecasting centers such as the European Centre for Medium range Weather Forecasts (ECMWF) and National Centre for Environmental Prediction (NCEP) have enriched the understanding of the Asian summer monsoon. The comprehensive understanding of the energy sources/sinks over the monsoon domain, and various mechanisms responsible for the maintenance of the summer monsoon circulation are crucial to ameliorate its simulation in various time scales. The recent efforts made by NCEP/NCAR (Kalney et al 1996), to use a frozen state of art analysis/forecast system and perform data assimilation using past data, from 1948 to the present, are laudable. The NCEP/NCAR reanalyses are research quality data sets suitable for multifarious purposes including climate trends and diagnostic studies. Several studies (Mo and Higgins 1996; Schmitz and Mullen 1996; Chen et al 1996 etc.) adduced this aspect. Although, some studies addressed the issue of the large-scale balances of vorticity and angular momentum over Asian summer monsoon (Oort and Chan 1977; Fein 1977; Mohanty and Ramesh 1994; Rao 2001), very few elucidated the maintenance of Asian summer monsoon during the evolution and established phases and compared it in various reanalyses/analyses. In this vein, this study aims to enunciate the maintenance of Asian summer monsoon through vorticity and angular momentum budgets. The objectives of the study are:

- to document the large-scale balances of vorticity and angular momentum during the evolution and established phases,

- to compare these balances in the NCEP/NCAR reanalysis and the NCMRWF operational analysis fields during the established period of the monsoon.

\section{Methodology}

The large-scale balance equations of vorticity and angular momentum are obtained, from the equations of motion and other conservation principles that atmosphere obeys, on simple mathematical transformations. The large-scale atmospheric systems ought to satisfy these balances at various time scales, in the observed as well as simulated atmosphere. It is well known that any time mean atmospheric circulation consists of a stable component, which remains almost constant or varies slowly over a time period, which is called the mean part, and another rapidly varying component, which changes very fast over a time period, which is called the eddy part. In general, tropical circulations are dominated by the mean component and extra-tropical circulations are dominated by the eddy component of the flow. Since Asian summer monsoon circulation is predominantly driven by mean component of the flow, we have bifurcated the time mean budgets into the respective mean and eddy budgets. In this study, we have elucidated the mean budgets only. The various budget equations are expressed in the flux form with pressure as the vertical coordinate.

The mean vorticity budget equation is designated as

$$
\begin{aligned}
& \frac{\overline{\partial \zeta}}{\partial t}+\nabla \cdot(\bar{\zeta} \bar{V})+\beta \bar{v}+\frac{\partial(\bar{\zeta} \bar{\omega})}{\partial P} \\
& =-(\bar{\zeta}+f) \bar{D}-\overline{k \cdot\left(\nabla \omega \times \frac{\partial v}{\partial P}\right)}+\bar{Z} .
\end{aligned}
$$

The first term on the left of equation (1) represents local variation of relative vorticity. The second and third terms indicate the horizontal flux divergences of relative and planetary vorticity respectively. The fourth term describes the vertical flux divergence of relative vorticity. Similarly, the first and second terms on the right hand side evince the vorticity generation due to stretching and tilting respectively. The final term designates the residue of vorticity (i.e., generation/dissipation from sub-grid scale processes).

The mean angular momentum budget equation is illustrated as

$$
\begin{aligned}
\frac{\overline{\partial M}}{\partial t}+\nabla & \cdot(\overline{M V})+\frac{\partial(\bar{M} \bar{\omega})}{\partial P} \\
& +(-f \bar{v} a \cos \varphi)=-\frac{\partial \bar{\phi}}{\partial \lambda}+\delta \bar{\phi}+\overline{F_{\lambda}},
\end{aligned}
$$

where $\bar{M}=\bar{u} a \cos \phi$.

In the equation (2), the first term on the left designates the local tendency of relative momentum. The second and third terms describe the 
horizontal and vertical flux divergences of relative momentum respectively. The fourth term evinces the horizontal flux divergence of omega momentum (or earth's momentum). In the same manner, the first and second terms on the right designate the generation/dissipation of momentum due to the pressure torque (i.e., east-west pressure gradient), and mountain torque respectively. The final term describes the frictional dissipation of momentum.

In this study, the budgets are computed using daily reanalysis as well as analysis fields. The terms representing local variation of various quantities in the respective budget equations are very small in terms of magnitude. Further, the vertical flux terms are insignificant. In this study, we elucidated the terms, which contribute significantly in the respective budgets for the maintenance of the summer monsoon circulation.

\section{Data and analysis procedure}

The present study is carried out making use of daily data comprising 0000 and 1200 UTC of NCEP/NCAR (henceforth NCEP) reanalysis for a forty year period (1958-97) consisting of May, June, July and August and NCMRWF operational analysis for a three year (1994-96) period consisting of June, July and August. The NCMRWF has been producing medium range forecasts since June 1994. The global data assimilation and forecast system is adapted from NCEP. The data for Asian summer monsoon domain $\left(15^{\circ} \mathrm{S}-45^{\circ} \mathrm{N}\right.$, $30^{\circ} \mathrm{E}-120^{\circ} \mathrm{E}$ ) is extracted from the global analysis/reanalysis. The basic meteorological fields considered for the study include geopotential height $(Z)$ and horizontal wind components $(u \& v)$ at ten mandatory levels $(1000,850,700,500,400,300$, $250,200,150,100 \mathrm{hPa}$ ). In the NCEP reanalysis, an additional two level data, one in the boundary layer $(925 \mathrm{hPa})$ and the other in mid-troposphere $(600$ $\mathrm{hPa}$ ) are included. Both NCEP and NCMRWF use spectral statistical interpolation (SSI) as the analysis module. The comprehensive details of the assimilation suite at NCMRWF and NCEP are provided in the studies of Parrish and Derber (1992). The details of the operational model at NCMRWF and NCEP model used for the generation of reanalysis are provided in earlier studies (Kanamitsu 1989). Although not many differences are envisaged in terms of dynamics and physics of both models, the horizontal and vertical resolutions are significantly different. The operational model at NCMRWF is T80L18 (80 waves with 18 vertical levels), and the NCEP model is T62L28 (62 waves with 28 vertical levels). The NCEP and NCMRWF models have seven and five levels in the boundary layer respectively. The models include parameterizations of all major physical processes such as convection, large-scale precipitation, shallow convection, gravity wave drag, radiation with diurnal cycle and interaction with clouds, boundary layer physics, surface hydrology, and vertical and horizontal diffusion processes. The main difference in the NCEP and NCMRWF model is the use of convective schemes namely simplified Arakawa-Schubert developed by Pan and $\mathrm{Wu}$ (1994) and modified Kuo (Anthes 1977) respectively. Other differences include, diagnostic cloud scheme of Campana et al (1994) used in NCEP and Slingo (1987) in NCMRWF. Further, a new soil model based on Pan and Mahrt (1987) is used in the NCEP model. The mass and velocity fields produced by the NCMRWF and NCEP models are of good quality and suitable for diagnostic studies. Instead of using vertical motion field from the archives, we made use of a kinematic technique (O'Brien 1970) in which the vertical integrated value of divergence in any particular column of the atmosphere becomes zero. The vertical motion values computed by the kinematic method described above have been used in the calculations of the various budgets.

\section{Results and discussion}

The comprehensive analysis of large-scale balances of vorticity and angular momentum associated with Asian summer monsoon circulation is presented as follows. The budgets for climate scale (40 year) are discussed initially, followed by the mean differences during the established phase in reanalysis and analysis data.

\subsection{Vorticity budget}

The cumulus convection plays a predominant role in modulating the summer monsoon circulation and also controls the vorticity and momentum budgets. A large number of earlier works (Holton and Colton 1972; Fein 1977; Sardeshmukh and Held 1984) showed imbalance in the vorticity budget over the summer monsoon domain. It was conceived that the balancing mechanism is provided by the generation of vorticity due to sub-grid scale convective processes. Further, the vorticity dynamics influence atmospheric response to a tropical heat source. Fein (1977) found that the production of vorticity by the divergent wind field is imbalanced over the tropical and sub-tropical belt. As a result, there is a negative (positive) vorticity from the regions of strong divergence (convergence). It was further suggested that in the regions of strong and persistent convection, such as 
the Tibetan plateau, deep cumulus clouds account for this transport. Sardeshmukh and Held (1984) demonstrated that the vorticity balance is found to be essentially non-linear as well as inviscid and there is a considerable balance between the stretching and horizontal advection of vorticity by the time mean flow in the vicinity of the Tibetan anticyclone, with much of the remainder being balanced by vertical advection and twisting terms. It is also found that the balance of vorticity at $850 \mathrm{hPa}$ is essentially between the planetary vorticity advection and the stretching term, while at $150 \mathrm{hPa}$ the primary balance is found between the stretching and the absolute vorticity advection terms. Mohanty and Ramesh (1994) delineated that the summer monsoon circulation is characterized by a net vorticity advection, which evinces that the entire region is quite unstable during the summer monsoon season with the production of vorticity within the domain itself for maintaining the circulation. It is balanced effectively by the vorticity generation due to sub-grid scale processes over the monsoon domain. The regional balance of vorticity is governed by the horizontal transport and production terms (Holopainen and Oort 1981, Chu et al 1981). However, over the summer monsoon domain, the horizontal transport terms are completely balanced by the vorticity generation due to sub-grid scale processes.

In figures 1-6, the left column panels correspond to the evolution period (May) and the right column panels denote the established period (JJA) of the summer monsoon. The horizontal flux divergence of relative vorticity is depicted in figure 1. Strong flux divergence is noticed over east Africa in the lower troposphere $(850 \mathrm{hPa})$ during the evolution period. Weak flux divergence is noticed over Burma and the adjoining south China Sea. On the other hand, weak convergence is noticed over the north Arabian Sea and the adjoining landmass. The strong flux divergence over east Africa is due to the cross-equatorial flow. Although, crossequatorial flow makes its presence during the evolution stage, the intense flow takes place during the established phase of the monsoon. In the upper troposphere, flux convergence of relative vorticity is noticed over northeast India, Burma and south China Sea. However, east Africa, Arabian Sea and the adjoining Arabia and Indian peninsula characterize flux divergence. The net tropospheric distribution of horizontal advection of relative vorticity (figure 1c) shows convergence over Arabia, northeast India and Indo-China peninsula. Weak flux divergence is noticed over east Africa, which is attributed to the cross-equatorial flow in the lower troposphere.

The sectoral average $\left(30^{\circ} \mathrm{E}-120^{\circ} \mathrm{E}\right)$ during the evolution phase of the summer monsoon (figure 1d) shows flux divergence of relative vorticity in the lower troposphere between $15^{\circ} \mathrm{S}$ and $25^{\circ} \mathrm{N}$ which is attributed to the low level flux divergence noticed off east Africa and the adjoining western Indian Ocean. The divergence of vorticity indicates the transport of vorticity from the monsoon domain to extra-monsoon regions. This feature connotes that the monsoon domain is a source region of vorticity. However, north of $25^{\circ} \mathrm{N}$, a weak convergence is noticed. In the upper troposphere, a zone of flux divergence is characterized between $15^{\circ} \mathrm{N}$ and $30^{\circ} \mathrm{N}$, flanked by weak convergence on either side. The geographical distribution of relative vorticity advection during the established phase indicates strong flux divergence over east Africa extending well into south Arabian Sea (figure 1e). However, weak convergence is noticed over the north Arabian Sea and south Bay of Bengal. In the upper troposphere, except over east Africa and Arabia the entire monsoon domain is characterized by convergence of vorticity, which is attributed to the anti-cyclonic type flow. The net tropospheric distribution shows strong flux divergence over east Africa, north central Indian Ocean and the adjoining south Indian peninsula and south China Sea. On the contrary, flux convergence is noticed over the western Indian Ocean, Bay of Bengal, and north Arabian Sea.

The sectoral average during the established phase (figure 1h) denotes strong flux divergence of vorticity compared to the evolution phase. The established phase of the monsoon is characterized by strong low level convergence and upper level divergence. The strong low level convergence facilitates the excess generation of vorticity, in turn excess transport out of the region. The upper level characteristics evince strong flux convergence of vorticity, which is attributed to the prevailing anticyclonic circulation in the upper troposphere. Further, the small flux divergence zone between $15^{\circ} \mathrm{N}$ and $30^{\circ} \mathrm{N}$, noticed during the evolution period shifted northwards and located around $30^{\circ} \mathrm{N}$ and $45^{\circ} \mathrm{N}$.

The horizontal advection of planetary vorticity is illustrated in figure 2 for the evolution and established periods of the summer monsoon. During the evolution period (figure 2a), the Arabian Sea and the Indian peninsula shows convergence of planetary vorticity. On the other hand, east Africa and the adjoining Indian Ocean, Burma and south China Sea indicate the flux divergence. The comparison with the horizontal advection of relative vorticity (figure 1) shows, that in the lower troposphere these two components balance each other in some regions and reinforce the divergence/convergence of vorticity in others. In other words, the advection of planetary vorticity opposes the advection of relative vorticity in 
Horizontal Flux of Relative Vorticity

MAY
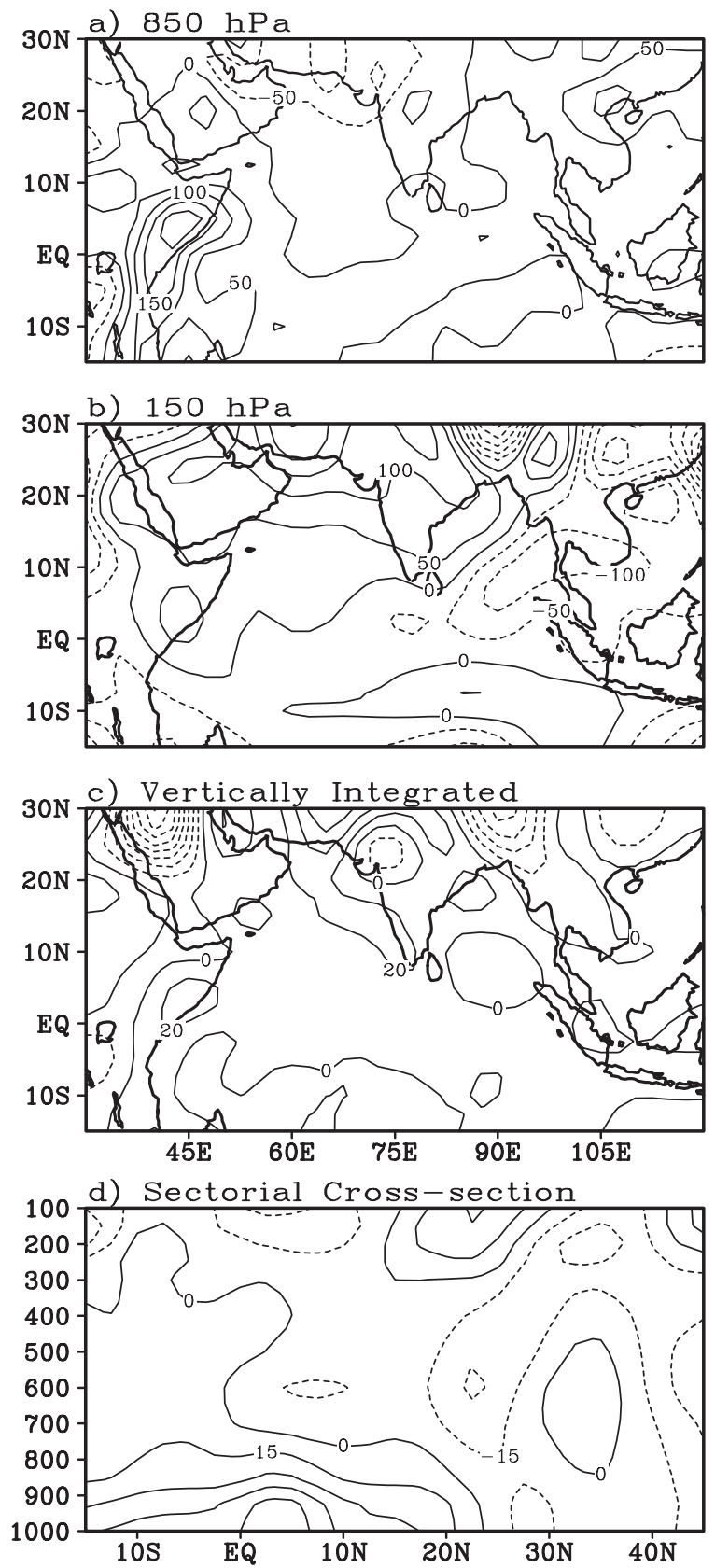

JJA
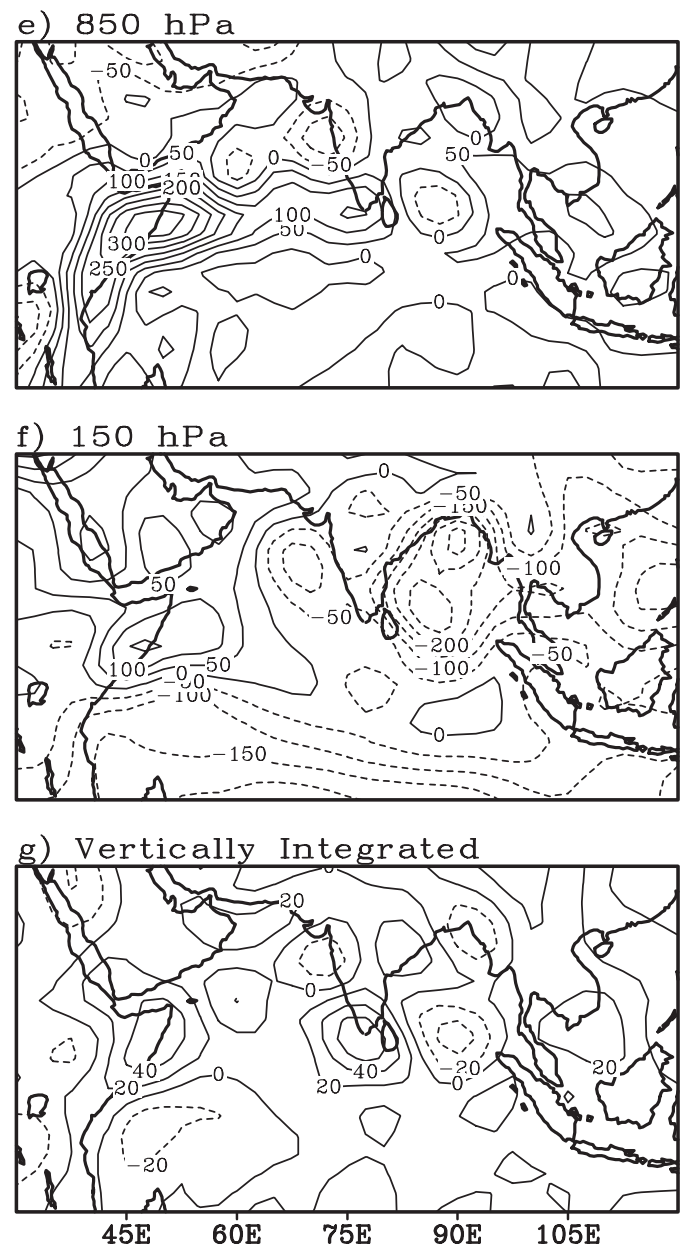

h) Sectorial Cross-section

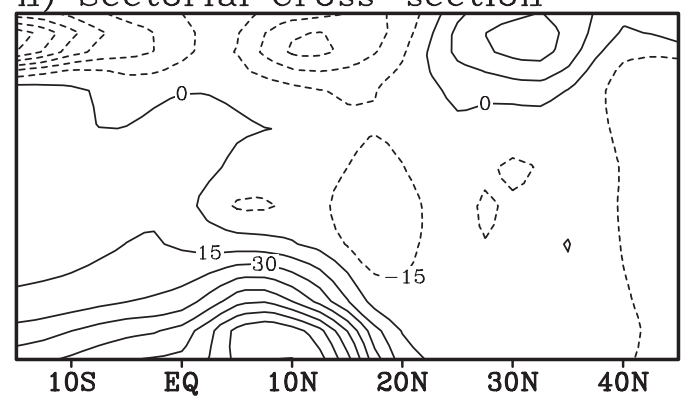

Figure 1. The horizontal advection of relative vorticity for the evolution (May) and established (JJA) periods of Asian summer monsoon corresponding to 1958-97 [Units: $10^{-12} \mathrm{~s}^{-1}$ for a, b, d, e, f \& h and $10^{-8} \mathrm{~N} \mathrm{~m}^{-3}$ for c \& g] (a) $850 \mathrm{hPa}$ for May (b) $150 \mathrm{hPa}$ for May (c) vertical integrated value for May (d) Sectoral $\left(30^{\circ} \mathrm{E}-120^{\circ} \mathrm{E}\right)$ average for May (e) $850 \mathrm{hPa}$ for JJA (f) $150 \mathrm{hPa}$ for JJA (g) vertical integrated for JJA (h) Sectoral $\left(30^{\circ} \mathrm{E}-120^{\circ} \mathrm{E}\right)$ average for JJA.

some zones and reinforces in other zones. In the upper troposphere (figure $2 \mathrm{~b}$ ), we noticed triangular sort of patterns, in which the upper triangle comprising the north Africa, Arabia, and the Indian subcontinent is characterized by divergence and the lower triangle consisting of the Indian Ocean and south China Sea is denoted by convergence. The interesting aspect to be noted is that both components cancel each other in some regions and reinforce in other zones in the upper troposphere also. Nevertheless, the predominance of relative vorticity advection ensures that their sum is non zero. The vertical integrated pattern during the evolution period (figure 2c) shows divergence of planetary vorticity along the coast of east Africa, Arabia and the Bay of Bengal. On the contrary, convergence is noticed over the Arabian Sea and the Indian subcontinent exclud- 


\section{Horizontal Flux of Planetary Vorticity}
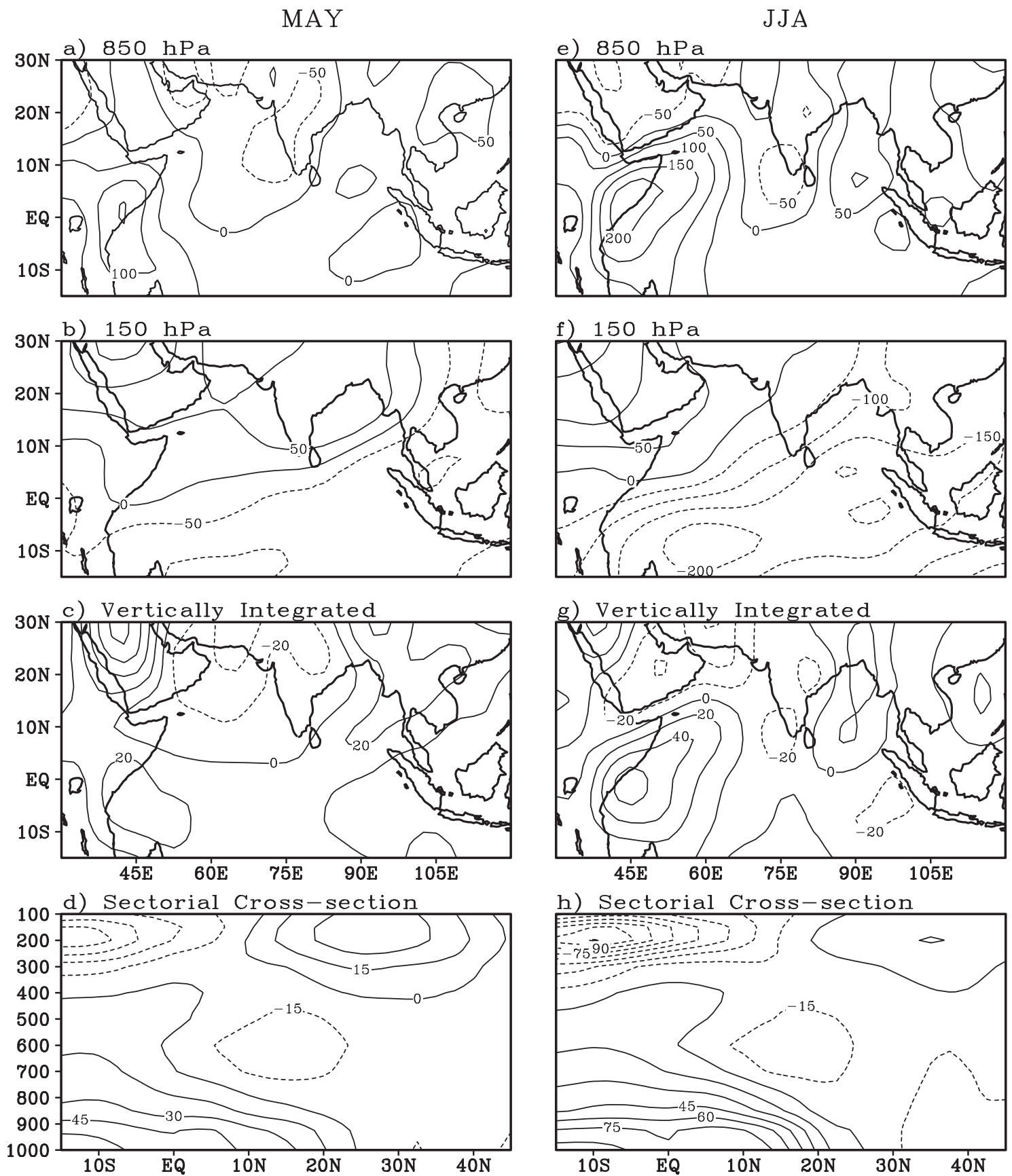

Figure 2. As in figure 1, but for horizontal advection of planetary advection.

ing the northeastern region. The sectoral crosssection (figure 2d) shows divergence in the lower troposphere between $15^{\circ} \mathrm{S}$ and $10^{\circ} \mathrm{N}$ and convergence in the upper troposphere between $10^{\circ} \mathrm{N}$ and $45^{\circ} \mathrm{N}$. In the middle troposphere, weak convergence is noticed. The lower tropospheric divergence is explained by the southerly flow and the upper level convergence is denoted by the northerly flow. During the evolution phase, the upper level return flow (northerly flow) is apparently weak.
The horizontal advection of planetary vorticity for the established phase of monsoon is indicated in figures $2(\mathrm{e})$ through $2(\mathrm{~h})$. The lower tropospheric features denote strong divergence off east Africa and the adjoining western Indian Ocean, Bay of Bengal and south China Sea. Convergence is characterized over Arabia, Arabian Sea and the peninsular India. As far as the balancing mechanism is concerned, though the advection of planetary vorticity offsets the advection of relative vorticty, the latter is more dominant even during the estab- 
lished period. Further, in the lower troposphere they balance each other only over the Bay of Bengal. Elsewhere, the combined effect of these two terms necessitate another dominant generation term to commensurate the balance. In the upper troposphere (figure $2 \mathrm{f}$ ), the pattern is more or less similar to the evolution phase, but with amplified strength. Basically, the advection of planetary vorticity is predominantly driven by the meridional component of the wind. The increase in low level southerlies and upper level northerlies is responsible for amplification of advection of planetary vorticity during the established phase. The vertical integrated pattern (figure $2 \mathrm{~g}$ ) indicates strong divergence of planetary vorticity off east Africa, the Bay of Bengal and south China Sea. Convergence is denoted over Arabia, the Arabian Sea, Indian peninsula and Indonesia. It is evident from the pattern (figure $2 \mathrm{~g}$ ), that the advection of planetary vorticity partly balances the relative vorticity over most of the monsoon domain except over east Africa, where both denote divergence. The sectoral cross section (figure $2 \mathrm{~h}$ ) evinces similar features as that of the evolution period, with a conspicuous difference of strong intensity during the established period. As explained earlier, the flow intensification during the established period is responsible for increase in the strength of planetary advection. The divergence zone noticed in the upper troposphere between $10^{\circ} \mathrm{N}$ and $45^{\circ} \mathrm{N}$ during the evolution period, weakened considerably.

The generation of vorticity due to stretching of isobars for the evolution and established periods is indicated in figure 3. Positive/negative values evince generation of cyclonic/anti-cyclonic vorticity. The lower tropospheric features (figure 3a) denote generation of cyclonic vorticity over the east and north Africa, Arabia, peninsular India, Pakistan, Burma and the south China Sea. On the other hand, generation of anti-cyclonic vorticity is noticed over the Persian Gulf, the Arabian Sea and north India. The generation depicts the balance with the advection terms over east Africa, the Arabian Sea, Bay of Bengal and south China Sea. Nevertheless, the generation is dominant in certain zones namely Arabia, peninsular India and Indo-China. This excess generation is balanced by horizontal advection of vorticity due to eddies (Sardeshmukh and Held 1984). In the upper troposphere (figure 3b) the Indian subcontinent, Arabia depict strong generation of cyclonic vorticity, whereas the Bay of Bengal and south China regions denote strong generation of anti-cyclonic vorticity. In the upper troposphere, ostensibly the balance is governed by the advection terms and the generation due to stretching. The vertical integrated generation of vorticity during the evolution period (figure 3c) depicts production of cyclonic vortic- ity over north Africa, Arabia, peninsular India, the Bay of Bengal and south China Sea. However, the Arabian Sea, Indian Ocean and Indo-China regions indicate generation of anti-cyclonic vorticity. The net tropospheric generation of vorticity is apparently balanced by the two advection components. The sectoral average during the evolution phase (figure $3 \mathrm{~d}$ ) indicates cyclonic vorticity in the lower troposphere and anti-cyclonic vorticity in the middle troposphere. However, in the extra-tropics, the reverse pattern, i.e., anti-cyclonic vorticity in the lower troposphere and cyclonic vorticity in the upper troposphere are denoted. The balancing requirement also shows that the vorticity generated in the monsoon domain is transported horizontally by the two advection terms of relative and planetary vorticity components.

The generation of vorticity due to stretching during the established phase (figure 3e) depicts strong generation of cyclonic vorticity over north Africa, Arabia, peninsular India, the Bay of Bengal and south China Sea. However, generation of anti-cyclonic vorticity is noticed over the Persian Gulf, the Arabian Sea, and portions of south China in the lower troposphere. The balance requirements evince that the generation due to stretching balances most of the divergence/convergence delineated by the advection terms. However, over certain zones (e.g., east Africa) the generation by stretching alone cannot balance the divergence (transport) of vorticity. In this case, the vorticity generation due to sub-grid scale processes (which is estimated as residue in this study) contributes for production in order to balance the transport (Sardeshmukh and Held 1984). However, this term compensates the balance only during the established period, due to the fact that the very existence of the term is attributed to profound cumulus convection, which is feasible during the established phase of monsoon. In the upper troposphere, the generation term (figure 3f) indicates strong production of anti-cyclonic vorticity over most of the monsoon domain except north India, east Africa and Indo-China regions where weak generation of cyclonic vorticity is noticed. Further, the convergence indicated by relative and planetary vorticity advections are commensurated by the generation of anti-cyclonic vorticity by the stretching term. Evidently, the generation due to stretching balances the advection terms such as relative and planetary vorticity in the upper troposphere during the established phase. The vertical integrated (net tropospheric) generation during the established period (figure 3g) shows generation of cyclonic vorticity along east Africa, over Arabia, the Bay of Bengal and south China Sea. On the contrary, generation of anti-cyclonic vorticity is denoted over the Arabian Sea, the Indian Ocean and the Tibetan 
Generation of Vorticity

MAY
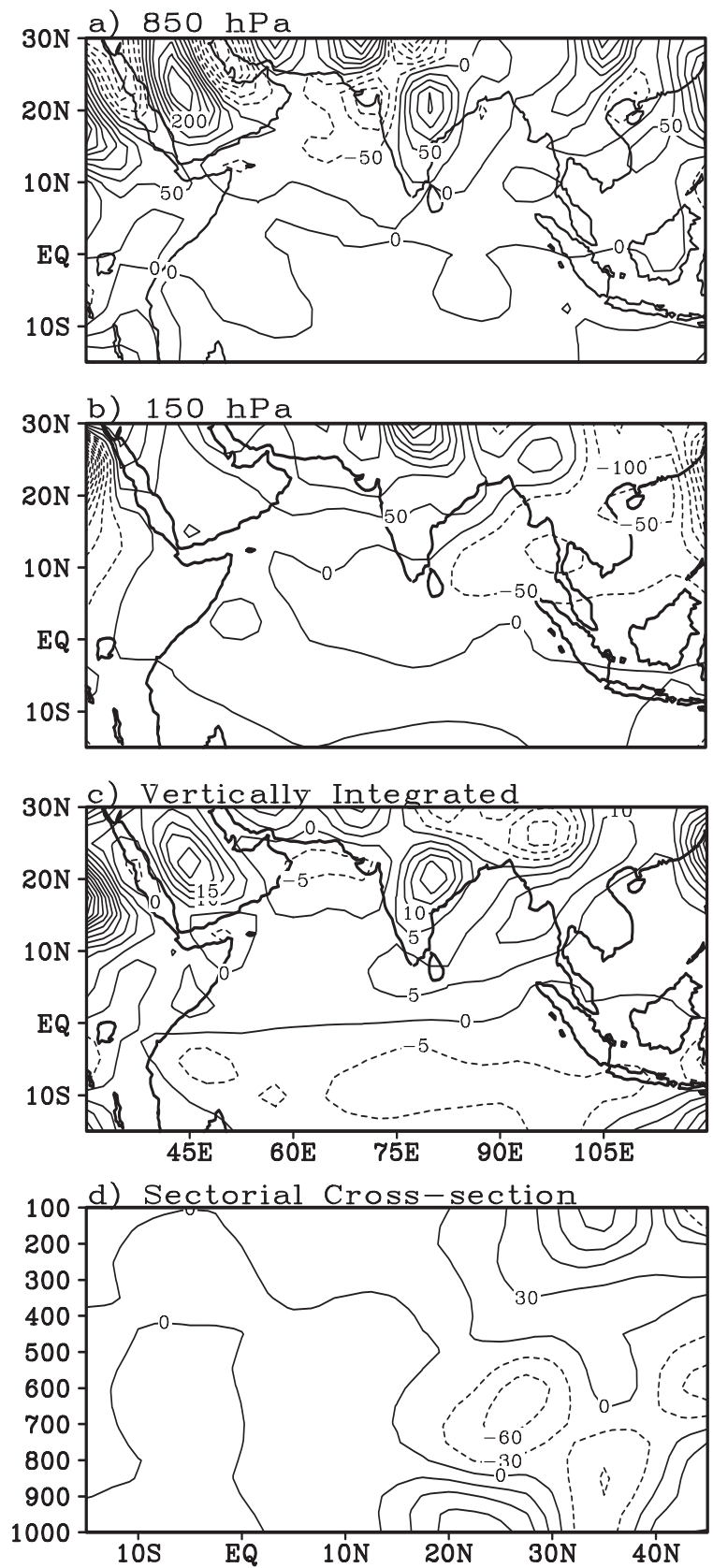

JJA
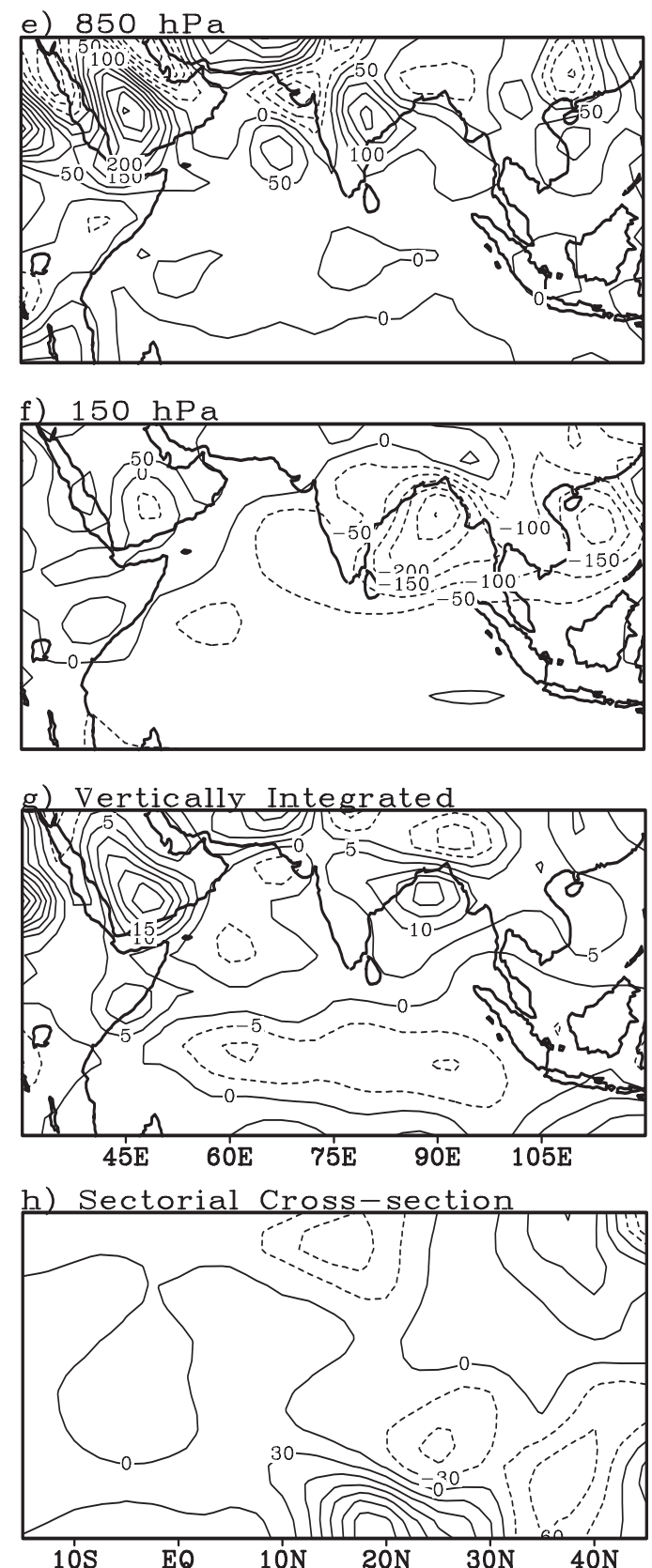

Figure 3. As in figure 1, but for generation of vorticity due to stretching.

Plateau. The generation due to stretching balances most part of the transportation of vorticity by the advection terms. However, in certain zones the transportation is not effectively balanced by the stretching during the established phase of monsoon circulation. The stretching is then aided by the vorticity generation due to sub-grid scale processes. The remarkable difference in the vorticity balance between evolution and established phases of the monsoon is the generation of vorticity due to sub-grid scale processes. This term (figure not presented) contributes only during the established period as the cumulus convection begets it. Further, this term effectively balances the transport along the stretching term. The sectoral crosssection of vorticity generation due to stretching is evinced in figure $3(\mathrm{~h})$ for the established period. Strong production of cyclonic vorticity is noticed in the lower troposphere of the monsoon domain. However, between $30^{\circ} \mathrm{N}$ and $45^{\circ} \mathrm{N}$ it shows generation of anti-cyclonic vorticity. In the upper and middle troposphere, mostly anti-cyclonic vorticity 
is generated over the monsoon domain. But the upper troposphere of the extra-tropics is characterized by generation of cyclonic vorticity. A comparison between evolution and established periods shows that the generation of cyclonic vorticity is stronger during the established period. Further, the generation of anti-cyclonic vorticity is noticed in the upper troposphere during the established phase of monsoon only. The balance requirements also indicate that during the established phase, the generation of vorticity by the stretching alone cannot balance the horizontal transport due to relative and planetary vorticities. The vorticity generation due to sub-grid scale processes along with the stretching term balances the vorticity transport out of the monsoon domain effectively.

\subsection{Angular momentum budget}

The angular momentum with respect to the earth's axis of rotation is one of the fundamental parameters used to characterize the general circulation of the atmosphere and climate (Oort and Peixoto 1983). The angular momentum for the atmosphereocean-solid earth system is invariant. Hence, it is an important quantity to consider while studying the general circulation of the atmosphere. The angular momentum of the atmosphere changes as it interacts with the oceans and solid-earth constantly. Basically the action of mountain torque as well as frictional torque changes the angular momentum. However, in the regional balance of the angular momentum, the flux transport and the zonal pressure gradient terms become equally important. The zonal pressure gradient or the pressure torque results from the pressure differences between the eastern and western boundaries. Further, the existence of mountain torque is due to the topographic barriers. In the regional angular momentum balance, the significant terms are the flux divergence, generation and dissipation terms. The pressure torque generates the angular momentum over the summer monsoon domain. The balance over the Indian summer monsoon domain is to a large extent governed by horizontal flux transport terms such as omega and relative momentum and angular momentum generation due to the pressure torque (Oort and Chan 1977).

Earlier studies (Mohanty and Ramesh 1994; Rao 2001) revealed that the dominant terms in the large-scale balance of angular momentum over the monsoon domain are the horizontal flux divergences of omega and relative momenta as well as pressure torque. The horizontal flux divergence of omega momentum for the evolution and established periods of monsoon is illustrated in figure 4 . In the lower troposphere, flux divergence of omega momentum (or earth's momentum) is characterized over the southwest Indian Ocean, Arabian Sea, Indian subcontinent and Iran regions. On the other hand, flux convergence is noticed over east-central Africa, Arabia, Bay of Bengal, IndoChina and south China. In the upper troposphere (figure 4b), omega momentum shows strong flux convergence over the entire monsoon domain barring south China, where flux divergence of omega momentum is noticed. The vertical integrated distribution (figure 4c) during the evolution period shows strong flux convergence over Arabia, northeast India, Burma and Bangladesh. On the contrary, strong flux divergence of omega momentum is noticed over the Arabian Sea and Indian peninsula. The sectoral cross-section during the evolution period (figure 4d) depicts divergence between $15^{\circ} \mathrm{S}$ and equator and also between $25^{\circ} \mathrm{N}$ and $45^{\circ} \mathrm{N}$. It also indicates divergence in the middle troposphere. However, between equator and $25^{\circ} \mathrm{N}$ in the lower troposphere it shows convergence. The upper troposphere features are dominated by strong convergence of omega momentum during the evolution period.

The horizontal flux of omega momentum distribution in the lower troposphere indicates strong flux divergence over southwest Indian Ocean, Arabia, and the Indian peninsula. On the other hand, flux convergence is denoted over east Africa, the Bay of Bengal, northeast India, Bangladesh, Burma and south China Sea. The major difference in the omega momentum distribution between the evolution and established periods is the strong flux divergence/convergence over the respective zones. In the upper troposphere (figure 4f), strong flux divergence is noticed over southeast Arabian Sea, the Bay of Bengal, Indian peninsula, northeast India, Bangladesh, Burma and south China Sea. On the other hand, rest of the monsoon region shows strong flux convergence. The main difference between the evolution and established periods is the extension of flux divergence zone well up to the Indian peninsula. The vertical integrated distribution of omega momentum during the established phase of monsoon evinces flux convergence over north Arabia, northeast India and Bangladesh. However, flux divergence is noticed over south Arabia, the Arabian Sea, Indian peninsula and south China Sea. The sectoral cross-section (figure $4 \mathrm{~h}$ ) evinces strong convergence over the monsoon domain between equator and $30^{\circ} \mathrm{N}$ in the lower troposphere. It indicates divergence in the southern hemispheric tropics and extra-tropics of northern hemisphere in the lower troposphere. The upper tropospheric features are mostly dominated by strong flux convergence. On the other hand, over the monsoon domain in the upper troposphere weak divergence is noticed, which is notably absent 
Horizontal Flux of Omega Momentum

MAY
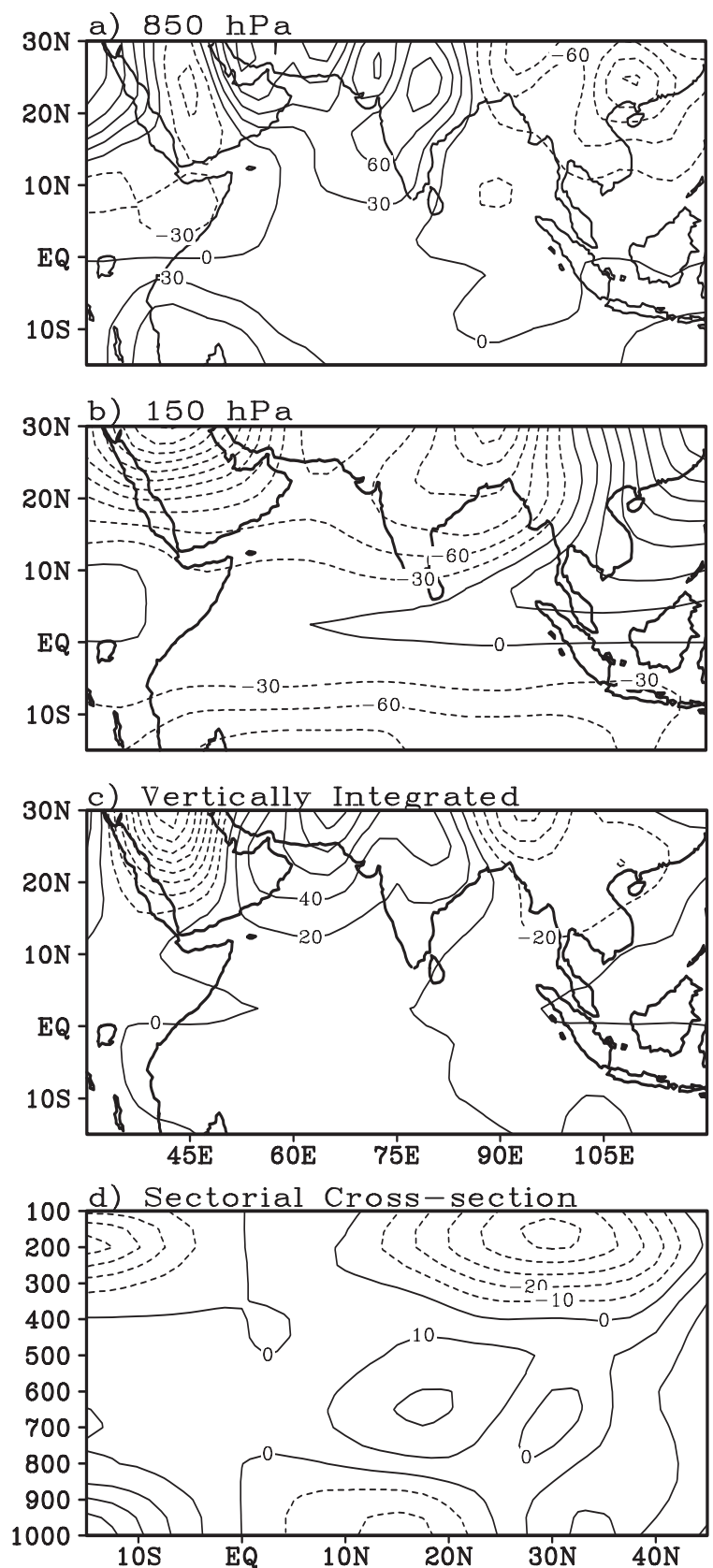

JJA
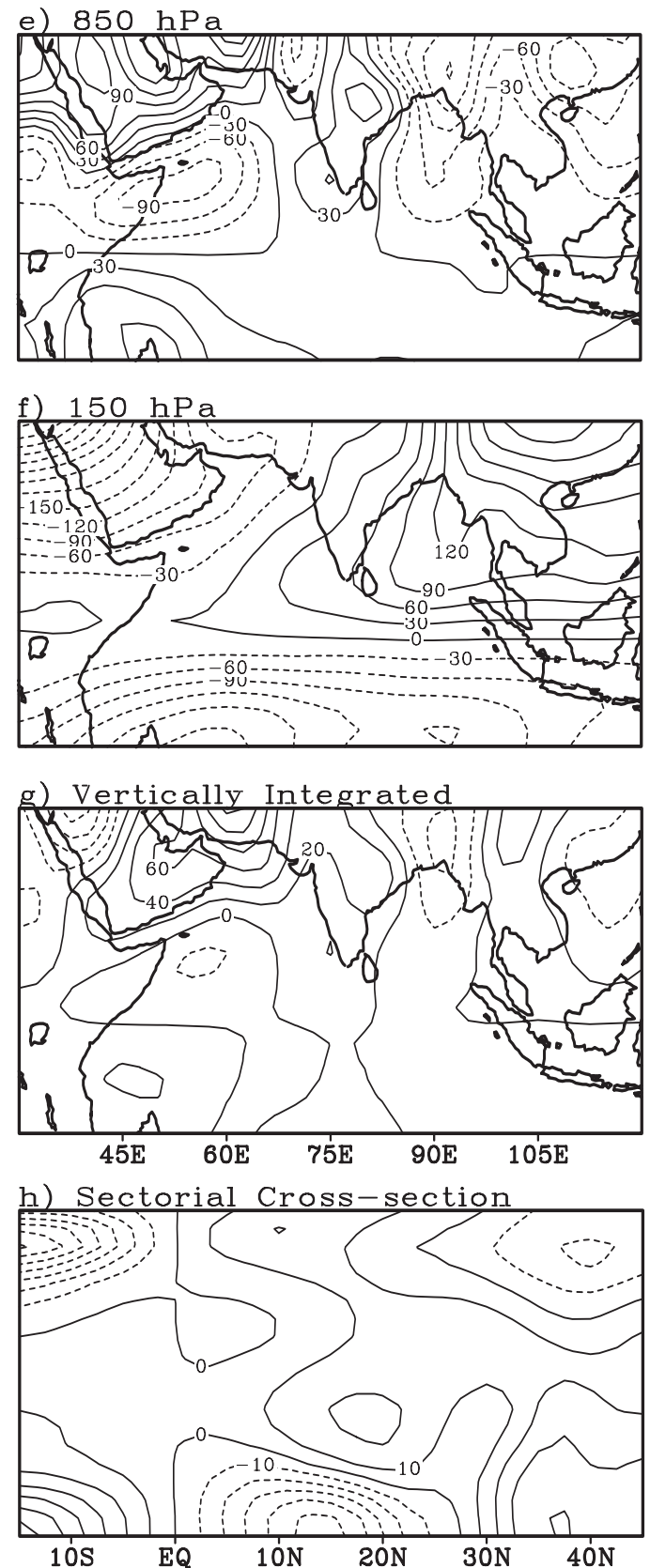

Figure 4. The horizontal flux divergence of omega momentum for the evolution (May) and established (JJA) periods of Asian summer monsoon corresponding to 1958-97 [Units: $10^{14} \mathrm{~m}^{4} \mathrm{~s}^{-2}$ for a, b, d, e, f \& h and $10^{5} \mathrm{~kg} \mathrm{~s}{ }^{-2}$ for c \& g] (a) $850 \mathrm{hPa}$ for May (b) $150 \mathrm{hPa}$ for May (c) vertical integrated value for May (d) Sectoral $\left(30^{\circ} \mathrm{E}-120^{\circ} \mathrm{E}\right)$ average for May (e) $850 \mathrm{hPa}$ for JJA (f) $150 \mathrm{hPa}$ for JJA (g) vertical integrated for JJA (h) Sectoral $\left(30^{\circ} \mathrm{E}-120^{\circ} \mathrm{E}\right)$ average for JJA.

during the evolution period. The major difference during the established period is the reduction in the strength of upper tropospheric convergence and increase in the strength of lower tropospheric convergence.

The horizontal flux divergence of relative momentum for the evolution and established periods is depicted in figure 5. During the evolution phase of the monsoon, the relative momentum role in the angular momentum balance of the lower troposphere is minimal (figure 5a). On the contrary, in the upper troposphere (figure 5b) it evinces significant convergence over north India, Arabia, the Bay of Bengal and south China Sea regions. It shows divergence over south equatorial Indian Ocean and Indo-China regions. The pattern of relative momentum flux delineates that it opposes the omega momentum flux. In other words, it off- 
MAY
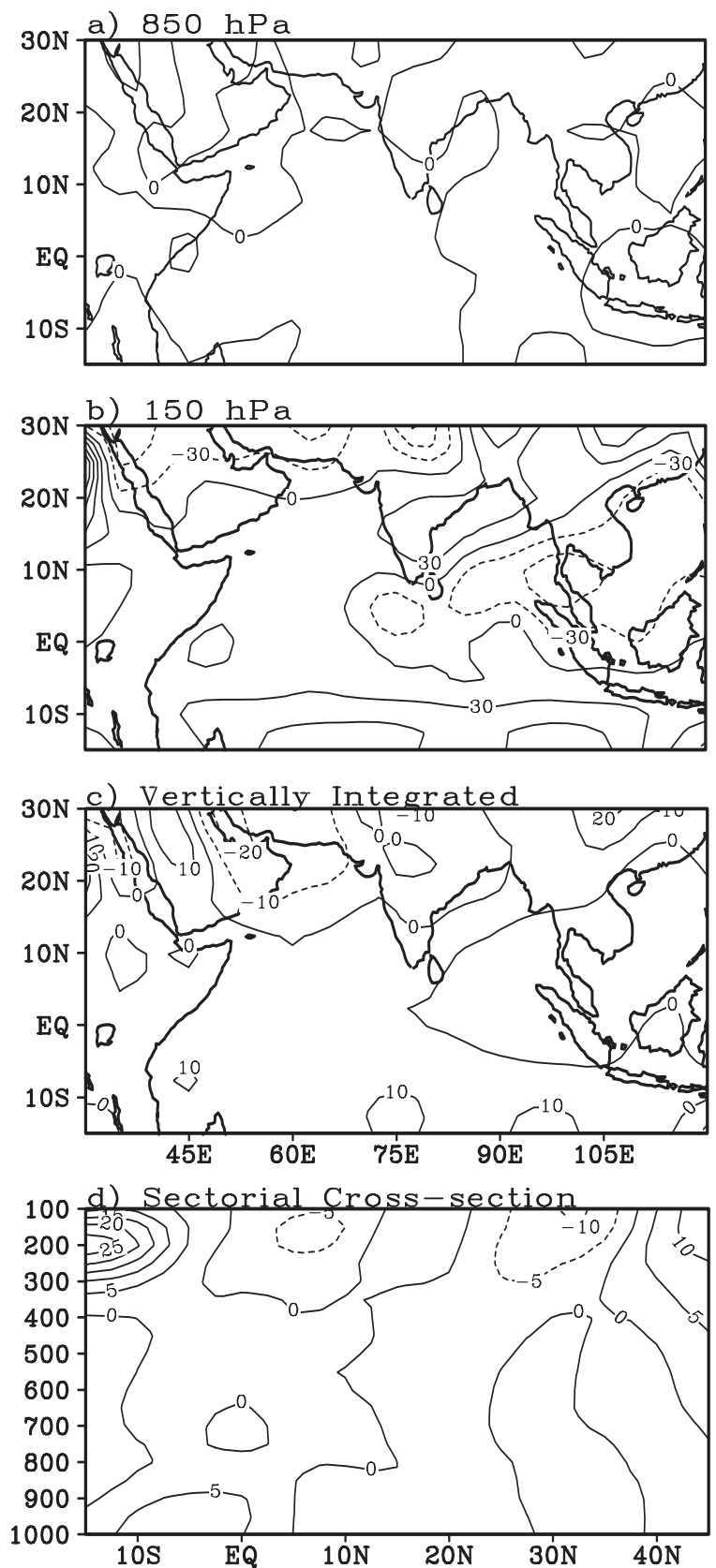
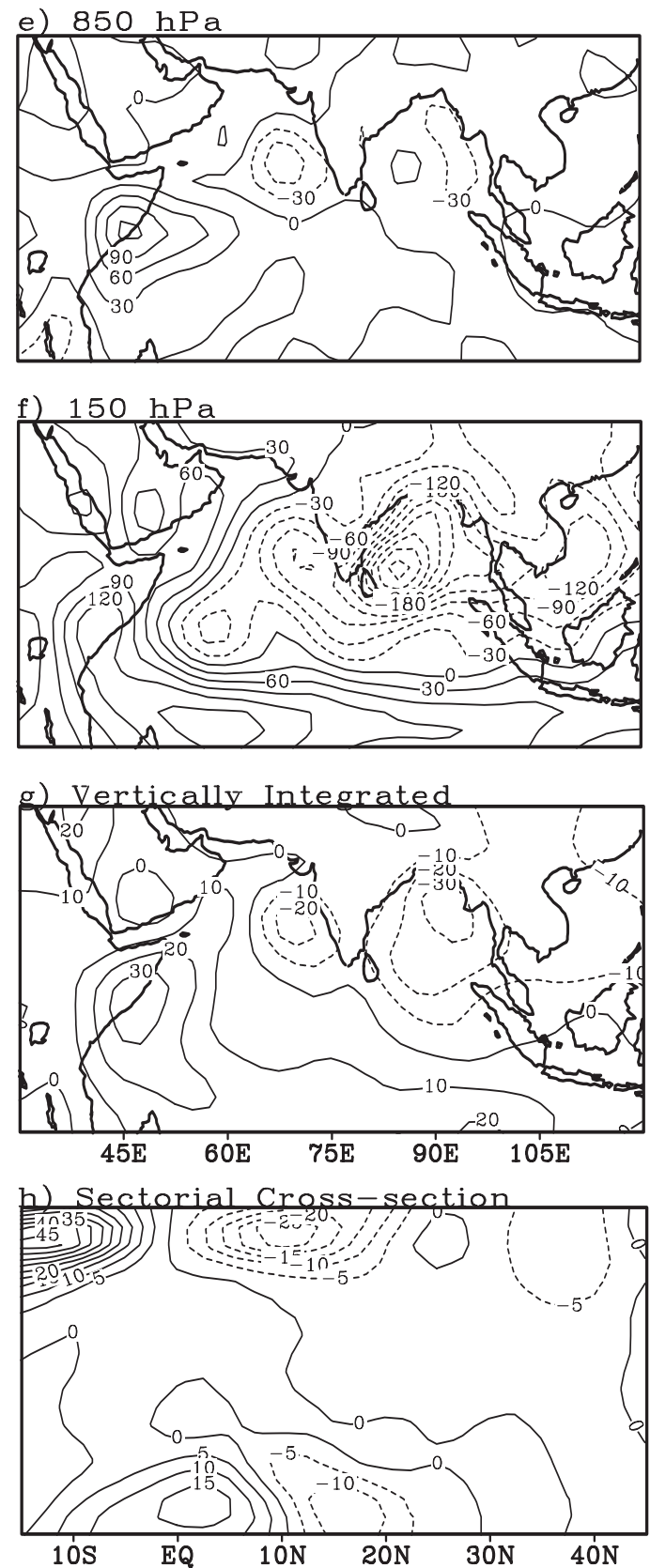

Figure 5. As in figure 4 but for horizontal flux divergence of relative momentum.

sets the effect of omega momentum flux in the balance of angular momentum. This aspect is in agreement with the earlier observations (Mohanty and Ramesh 1994; Rao 2001). The vertical integrated distribution (figure 5c) of relative momentum flux during the evolution period shows weak divergence over Indo-China and south equatorial Indian Ocean. However, weak convergence is characterized over east Arabia. The vertical integrated pattern also confirms our earlier observation that relative momentum flux partly balances the omega momentum flux over the monsoon domain. The sectoral mean (figure 5d) indicates weak convergence in the upper troposphere of the monsoon domain during the evolution period. On the other hand, strong divergence is indicated in the upper troposphere of the southern hemispheric tropics and northern hemispheric extra-tropics. The relative momentum flux during the established period (figure 5e) shows strong divergence off east Africa and the adjoining western Indian Ocean in the lower troposphere. Contrary to that, it shows weak 
convergence over southeast Arabian Sea and the Bay of Bengal. In the upper troposphere (figure 5f) the flux divergence off east Africa becomes very strong and extends over the entire south equatorial Indian Ocean. Further, unlike in the lower troposphere, the convergence indicates maximum over the south Bay of Bengal. Note that the effect of relative momentum is dominant in the upper troposphere. The vertical integrated relative momentum flux during the established phase of the monsoon (figure $5 \mathrm{~g}$ ) denotes strong divergence over east Africa and the adjoining Indian Ocean. However, convergence is noticed over the Arabian Sea, Bay of Bengal, Indian subcontinent and south China Sea. The flux convergence of momentum over the monsoon domain is necessary in order to maintain the surface westerlies against friction. The sectoral average of relative momentum flux during the established phase (figure 5h) shows strong convergence/divergence compared to the evolution period. This is attributed to increase in the strength of flow field during the established phase of the monsoon. The horizontal flux of relative momentum indicates divergence between $15^{\circ} \mathrm{S}$ and $10^{\circ} \mathrm{N}$ and convergence between $10^{\circ} \mathrm{N}$ and $30^{\circ} \mathrm{N}$ in the lower troposphere. However, it denotes strong divergence between $15^{\circ} \mathrm{S}$ and equator in the upper troposphere. The rest of the monsoon domain evinces convergence in the upper troposphere, in agreement with the geographical distribution noticed earlier (figure 5f). The interesting aspect illustrated by sectoral averages of both relative and omega momentum components is that both contribute for convergence of momentum over the monsoon domain. Note that between $10^{\circ} \mathrm{N}$ and $25^{\circ} \mathrm{N}$ both designate convergence in the lower troposphere (figure 5h), despite their cancelling tendency. The strong flux convergence by these momentum components connotes that the monsoon domain is basically a sink region of angular momentum.

The pressure torque (or east west pressure gradient) for the evolution and established phases of the monsoon is depicted in figure 6 . In the lower troposphere, during the evolution phase, the pressure torque (figure 6a) pattern mostly resembles the omega momentum term as these are the dominant terms in the angular momentum budget. Positive/negative values denote generation/dissipation of momentum. Generation of momentum is characterized over north Africa, east Arabia, the Arabian Sea, India excluding northeastern part and south-equatorial Indian Ocean. On the contrary, destruction of momentum is noticed over the Bay of Bengal, northeast India, Bangladesh, Burma and south China Sea. In the upper troposphere (figure $6 \mathrm{~b}$ ), mostly destruction is noticed barring the Bay of Bengal and south China Sea, where gener- ation of momentum is denoted. The vertical integrated pattern of pressure torque (figure 6c), shows generation of momentum over Africa, Arabian Sea and peninsular India. Further, it evinces destruction of momentum over Arabia, north India, Bay of Bengal, Burma and south China Sea. A comparison with other budget terms renders that the pressure torque balances the transportation terms. In other words, the momentum transported into the monsoon domain is effectively destructed by the pressure torque. This is evident from the geographical distributions. The sectoral mean pressure torque during the evolution period is illustrated in figure 6(d). It depicts destruction of momentum in the lower as well as upper troposphere. However, it also shows weak generation in the lower troposphere of the southern hemispheric tropics and the entire troposphere of the extra-tropics.

The pressure torque during the established period in the lower troposphere (figure 6e) shows more or less similar features as that of the evolution period with increase in the intensity. The upper tropospheric features (figure 6f) also evince the same characteristics. Ostensibly, the pressure torque denotes destruction of momentum in the lower as well as upper tropospheres of the monsoon domain. This feature necessitates the convergence of momentum over the monsoon domain in order to balance the destruction. Effectively, the convergence is vital for the maintenance of surface westerlies over the monsoon region. The vertical integrated pattern of the pressure torque (figure 6g) indicates some interesting features. Unlike the strong destruction noticed over Arabia during the evolution period, it denotes strong generation over Arabia during the established period. The pressure torque pattern bifurcates the monsoon domain into east and west parts, whereas the western part designates generation and the eastern part the dissipation of momentum. Further, the pattern also confirms our earlier observation that pressure torque balances the omega momentum term. The sectoral mean (figure $6 \mathrm{~h}$ ) during the established phase of the monsoon delineates similar features as that of evolution period except for the strength, which is attributed to the flow field.

\subsection{Comparison between NCEP and NCMRWF fields}

The maintenance of the summer monsoon in terms of large-scale balances of vorticity and angular momentum indicated by NCMRWF and NCEP are presented as follows. In the subsequent figures (a) corresponds to NCMRWF, (b) to NCEP and (c) indicates their difference (i.e., NCMRWF minus NCEP). 


\section{Pressure Torque}

MAY
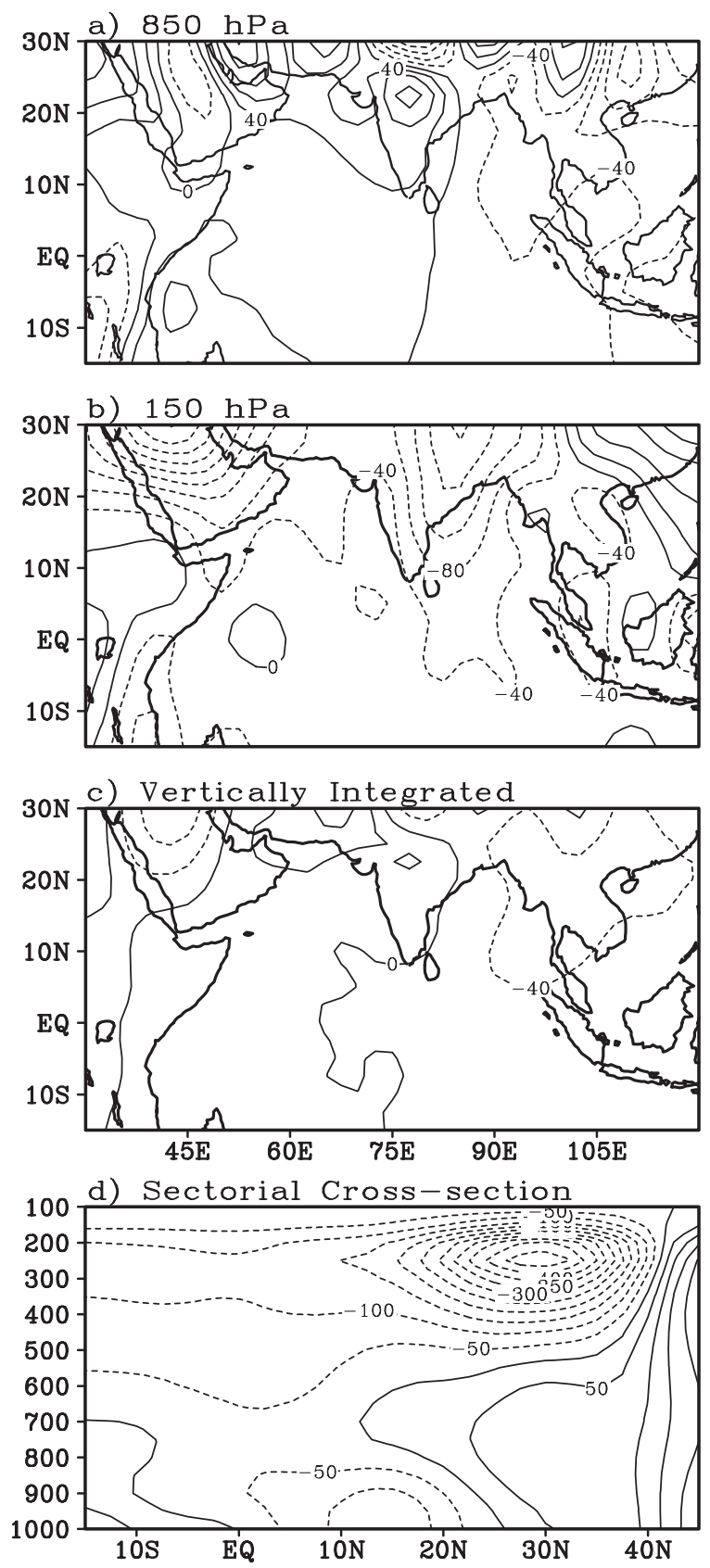

JJA
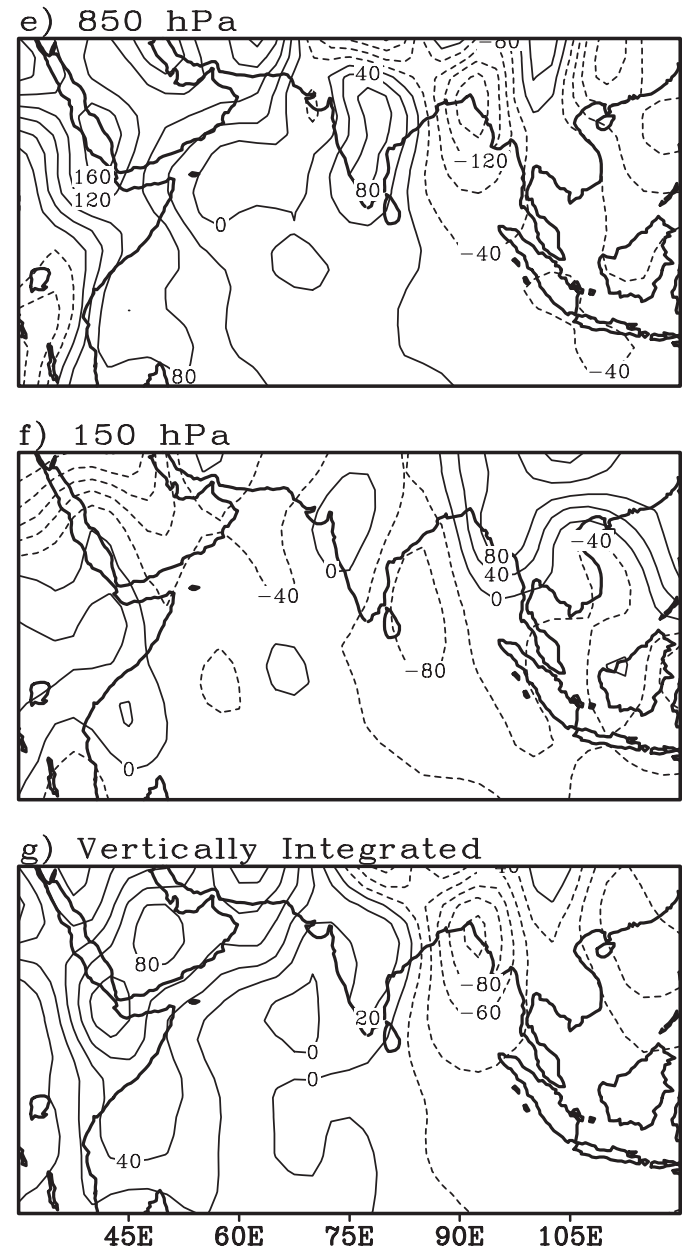

h) Sectorial Cross-section

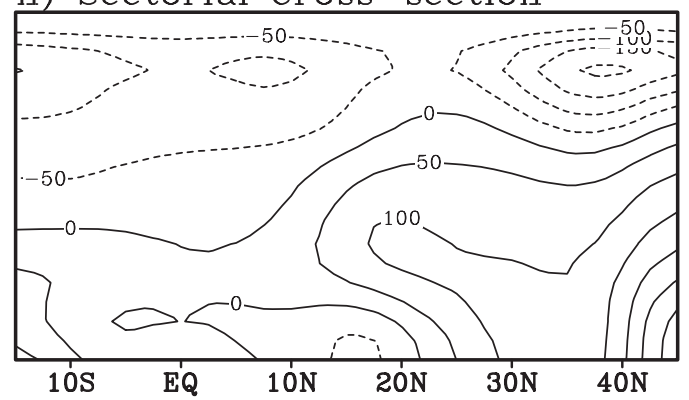

Figure 6. As in figure 4 but for pressure torque.

The geographical distributions of vertically integrated vorticity budget terms are shown in figures 7-9. The horizontal advection of relative vorticity (figures $7 \mathrm{a} \& \mathrm{~b}$ ) shows convergence over the Bay of Bengal and north Arabian Sea. It depicts divergence over the southeast Arabian Sea and adjacent peninsular India. Although the major features depicted by the NCMRWF analysis (figure 7a) and NCEP reanalysis (figure 7b) are identical, we noticed significant difference in terms of strength. The intensity of horizontal divergence indicated by NCMRWF fields is comparatively stronger. For example, the significant features such as the relative vorticity divergence over the northeast Africa and peninsular India denote the strength of the summer monsoon circulation. These are represented somewhat weaker in NCEP reanalysis.

As noticed in the earlier studies (Mo and Higgins 1996, Schmitz and Mullen 1996) the NCEP fields denoted oceanic bias. The planetary advection (figures $2 \mathrm{a} \& \mathrm{~b}$ ) shows divergence over the places of rel- 
Horizontal Flux of Relative Vorticity
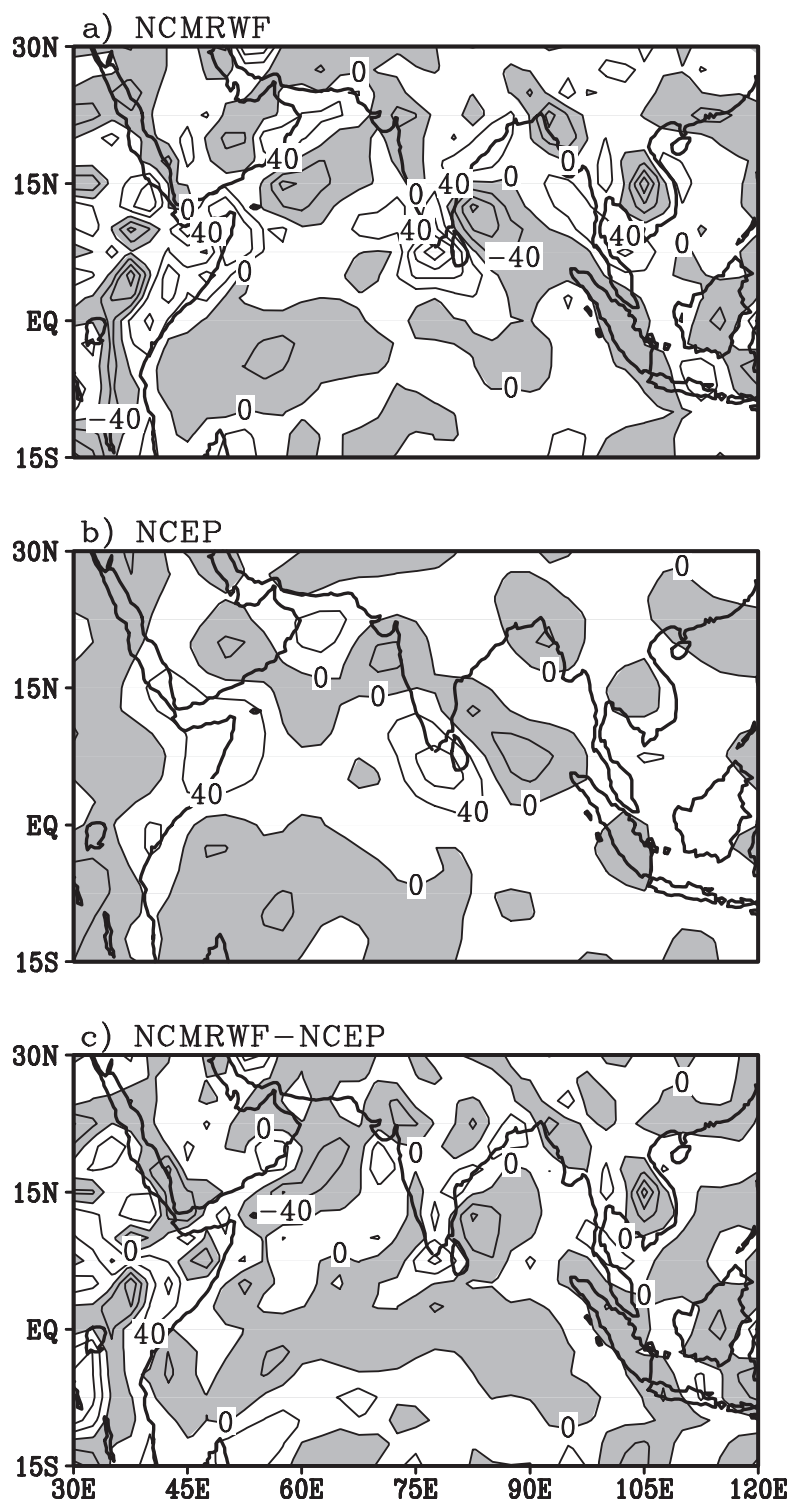

Figure 7. Geographical distribution of vertically integrated horizontal advection of relative vorticity for JJA 1994-96 [Units: $10^{-8} \mathrm{~N} \mathrm{~m}^{-3}$ ] (a) NCMRWF (b) NCEP (c) NCMRWF-NCEP (Contour interval: 40, negative values are shaded).

ative vorticity convergence, viz., the Bay of Bengal and off east Africa, as they oppose each other. The east African maximum is due to the strong cross equatorial meridional monsoonal flow. The horizontal advection indicated by NCMRWF fields (figure 8c) is stronger over east Africa, west Arabian Sea and east Bay of Bengal. The planetary advection to a large extent modulated by the meridional flow. This feature indicates that the intensity of monsoon circulation is comparatively stronger in the NCMRWF analysis. Further, these horizontal transportation terms connote that the monsoon region is characterized by net vorticity advection.
Horizontal Flux of Planetary Vorticity
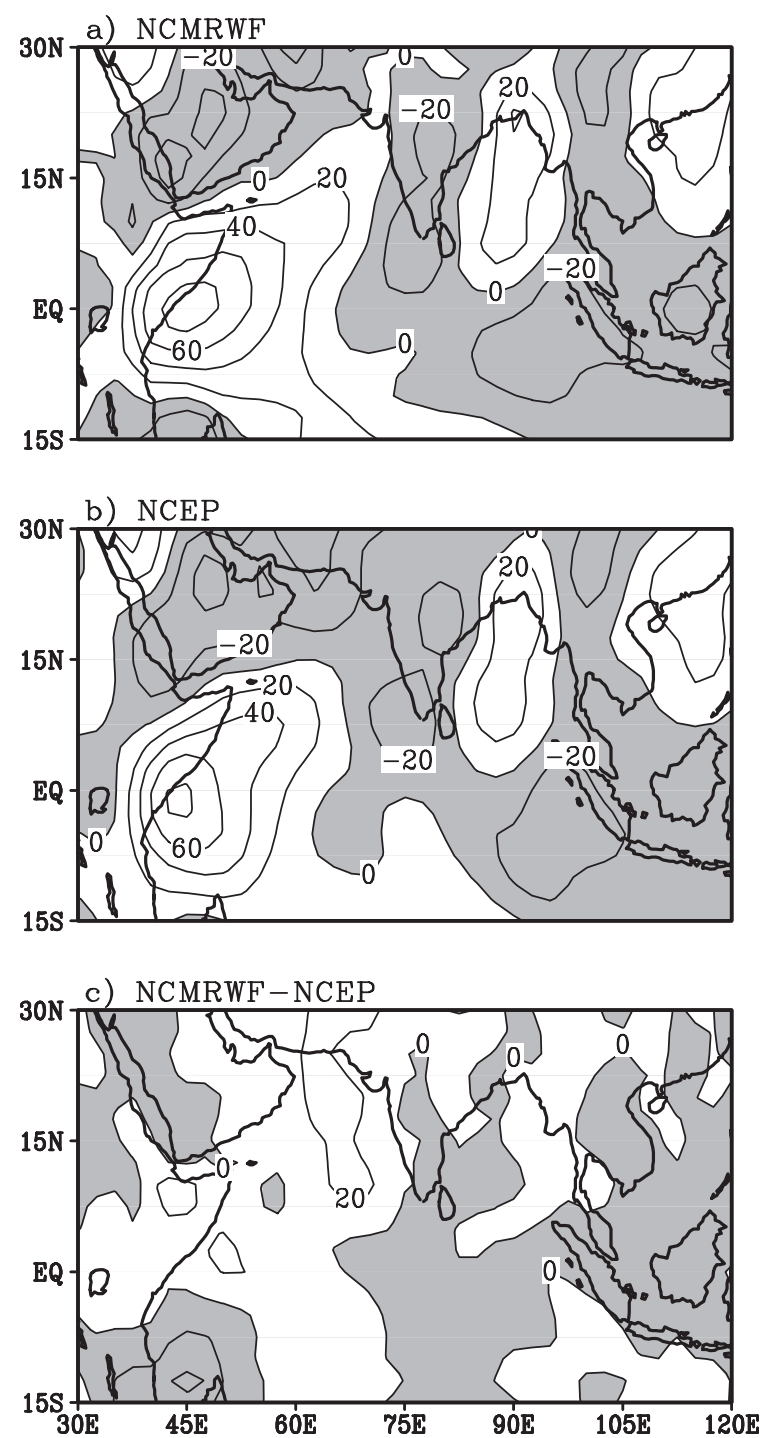

Figure 8. As in figure 7, but for horizontal advection of planetary vorticity. (Contour interval: 20, negative values are shaded).

The vertically integrated vorticity generation due to stretching is illustrated in figure 9 . The monsoon region is characterized by strong generation of vorticity except over the western segment. This generation is crucial to maintain the monsoon circulation. The strong generation is attributed to cyclonic circulation in association with the strong low-level convergence (Rao 2001). The generation of vorticity due to stretching is more over eastern India and north Africa in the NCMRWF analysis as compared to NCEP reanalysis.

The relative vorticity advection is predominant over the summer monsoon region, which is contributing for the horizontal transport of vorticity out of the domain. The planetary vorticity advection also contributes for the horizontal transport from the monsoon domain. The replenishing of 
Generation of Vorticity due to Stretching
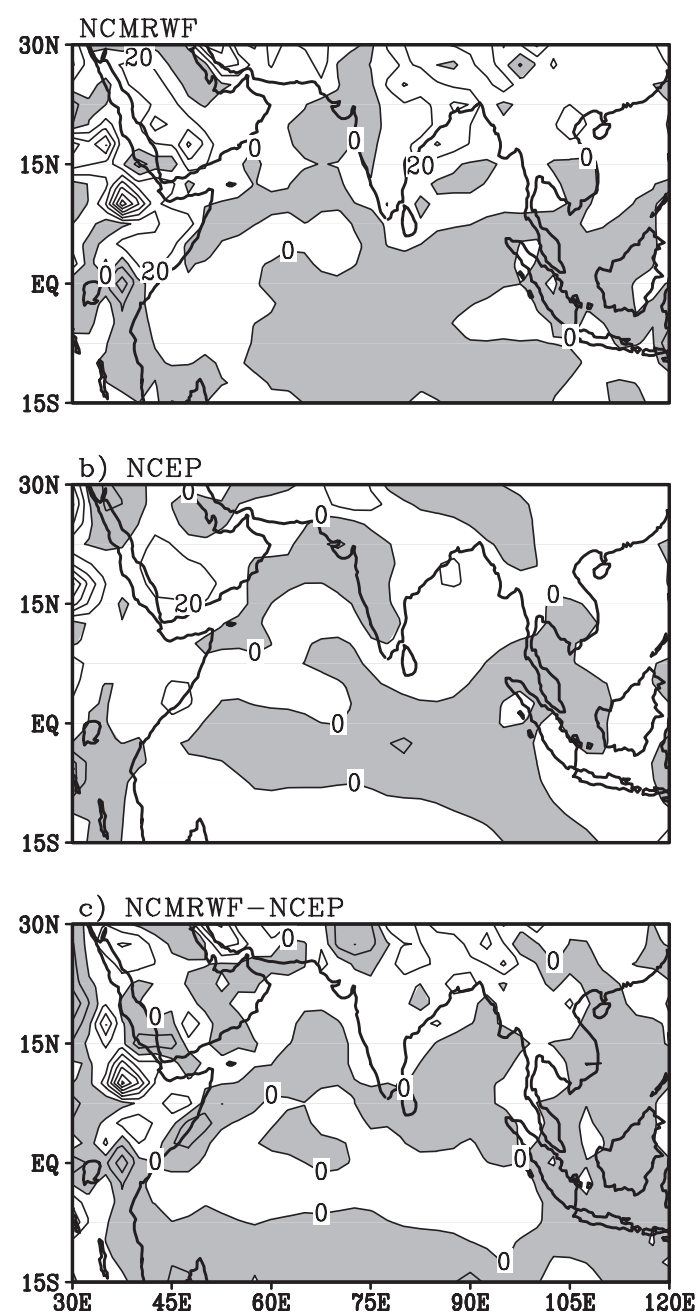

Figure 9. As in figure 7, but for generation of vorticity due to stretching. (Contour interval: 20, negative values are shaded).

vorticity is not effectively balanced by the vorticity generation due to stretching and tilting terms. The budget terms show that the horizontal transportation of vorticity is effectively balanced in the monsoon region by production of vorticity through sub-grid scale processes such as cumulus convection. Earlier studies (Reed and Johnson 1974; Chu et al 1981) indicated that the cumulus convection in the tropics could generate a large apparent source of vorticity. In general the vorticity budget terms delineated by NCMRWF indicates more strength as compared to NCEP. This feature in turn indicates that the intensity of the monsoon indicated by NCEP reanalysis is comparatively feeble. The difference may be explained as follows. The NCMRWF global data assimilation and forecast system (GDAFS) accepts most of the subcontinent observations, which are normally bypassed in NCEP GDAFS (personal com-
Horizontal Flux of Omega Momentum
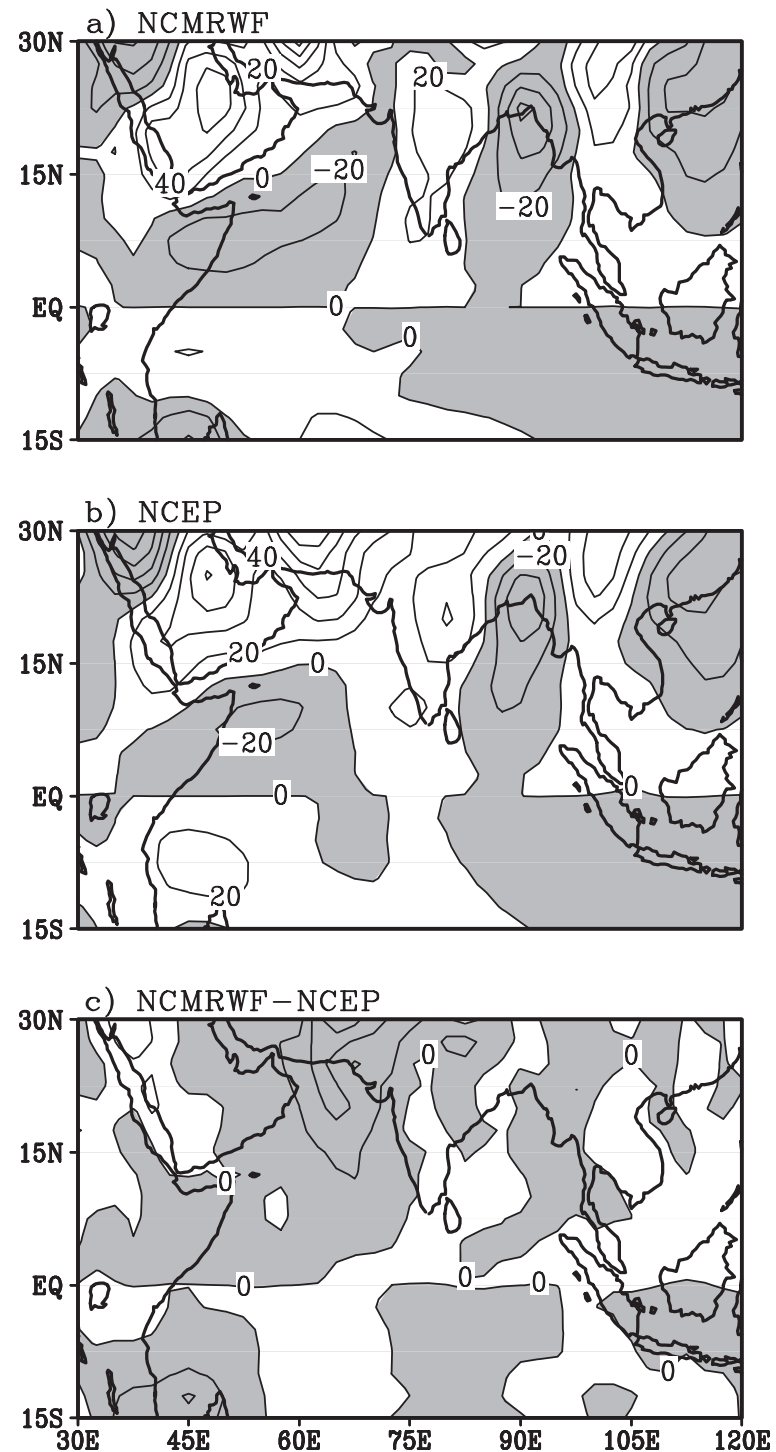

Figure 10. Geographical distribution of vertically integrated horizontal flux of omega momentum for JJA 1994-96 [units: $10^{5} \mathrm{~kg} \mathrm{~s}^{-2}$ ] (a) NCMRWF (b) NCEP (c) NCMRWF-NCEP (Contour interval: 20, negative values are shaded).

munication, Kalney). Presumably due to this reason, the circulation indicated by NCMRWF over landmass seems to be intense compared to NCEP. This is further corroborated by angular momentum budget.

In the regional angular momentum budget, the horizontal transport terms (omega momentum and relative momentum fluxes), the pressure torque (zonal pressure gradient), and frictional dissipation of momentum govern the balance. The vertically integrated geographical distributions of significant angular momentum budget terms are presented in figures 10-12. The horizontal flux of omega momentum (figures 10a \& b) indicates strong 

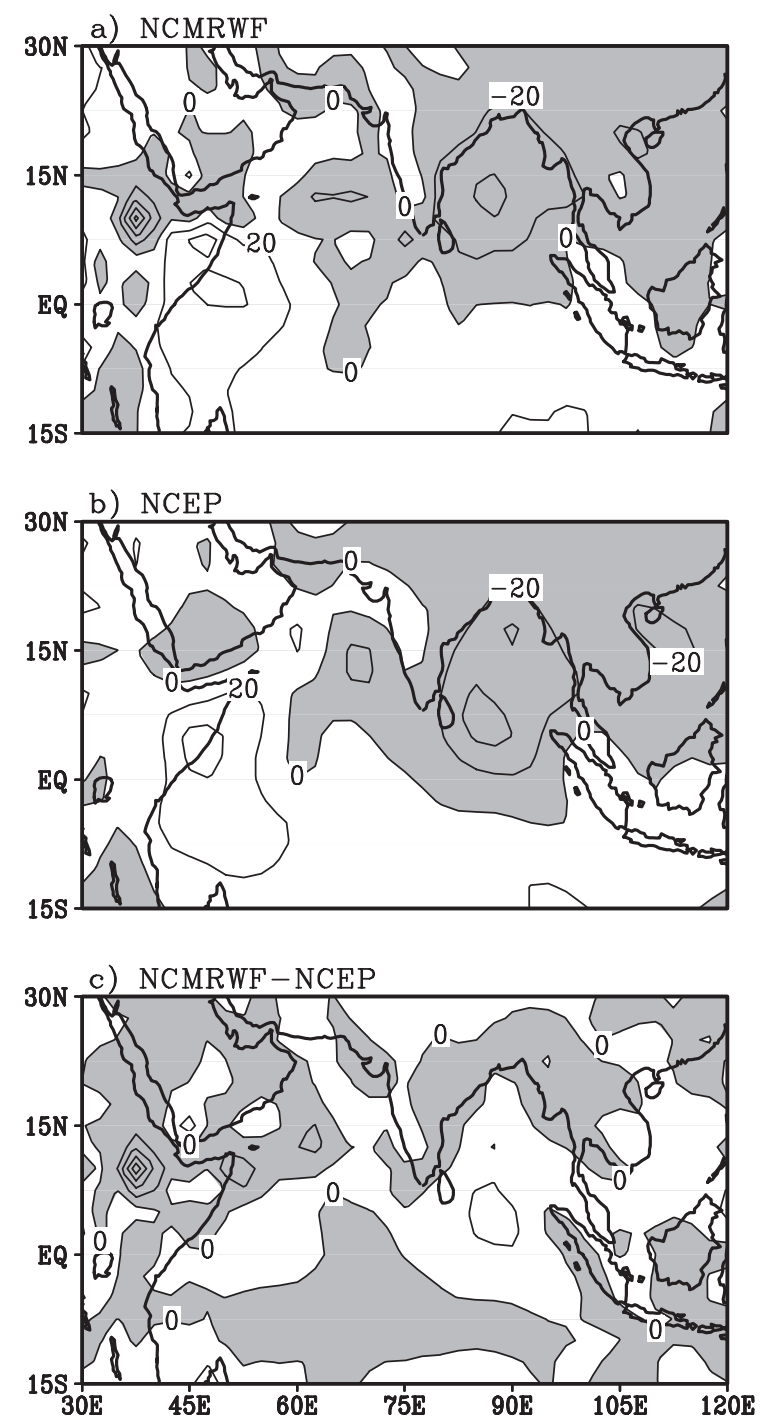

Figure 11. As in figure 10, but for horizontal flux of relative momentum.

divergence over eastern Arabian Sea and most part of landmass of India. Also flux convergence is depicted over east Africa, Bay of Bengal and west Arabian Sea. The divergence maximum is situated over the peninsular India and convergence maximum over the head Bay of Bengal. Despite delineating identical patterns and maxima of convergence and divergence in respect of horizontal flux of omega momentum, some differences are noticed (figure 10c). Compared to NCEP, the convergence flux indicated by NCMRWF is stronger. The relative momentum (figures 11a \& b) flux distribution shows flux convergence over the entire east Arabian Sea and the adjoining peninsular India as well as Bay of Bengal with a maximum over the Bay of Bengal. Interestingly, the omega momentum flux opposes relative momentum flux. The monsoon region is charac-
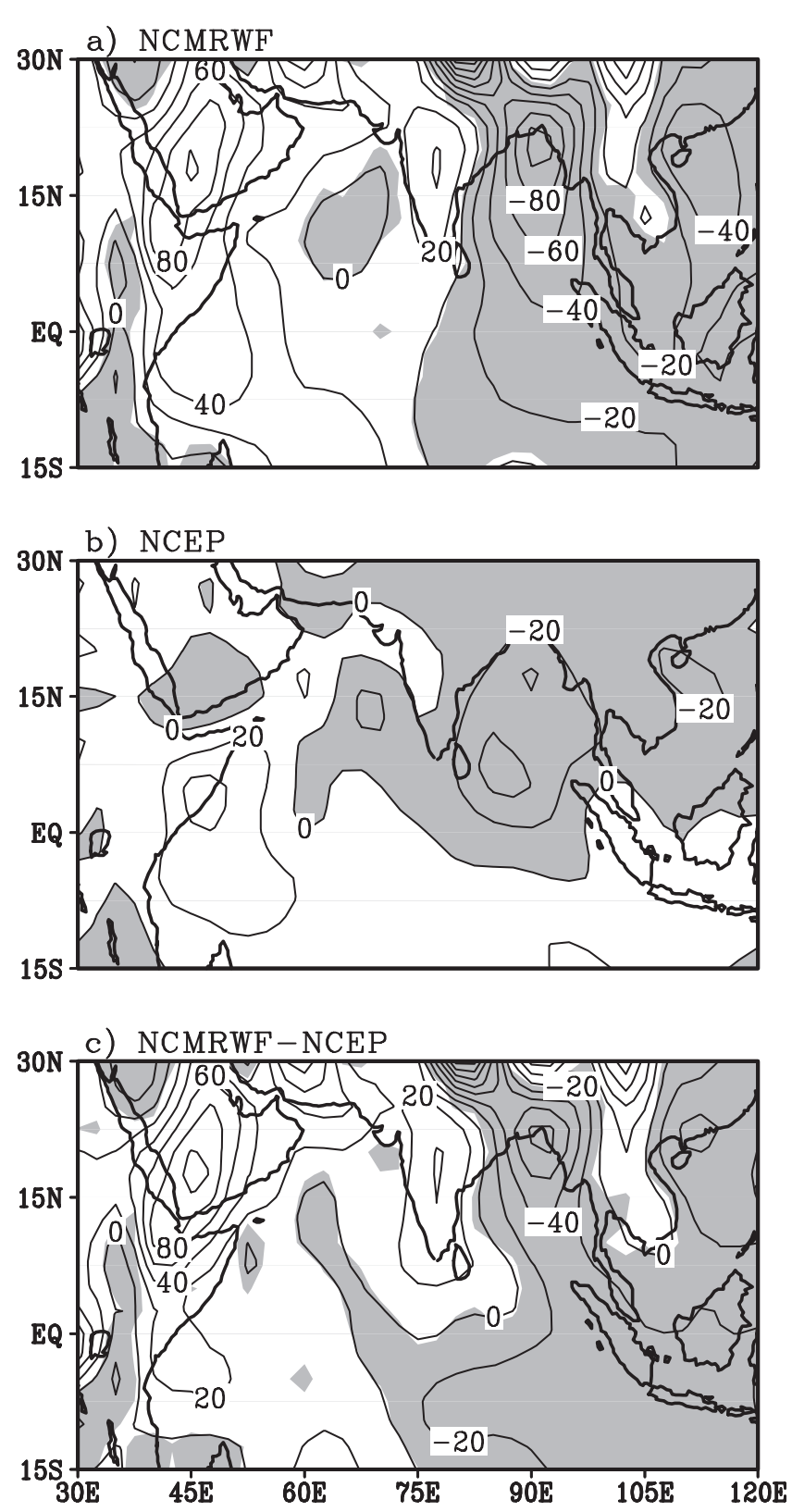

Figure 12. As in figure 10, but for pressure torque.

terized by momentum transport into the region in order to balance the surface westerlies against friction. This is illustrated by flux divergence pattern (figures $10 \& 11$ ). The horizontal flux of relative momentum indicates divergence off east Africa. In general, the convergence in the case of horizontal flux of omega momentum and relative momentum indicated by NCMRWF are stronger compared to NCEP. However, as we noticed in the vorticity budget, the magnitudes of these budget terms indicated by NCEP over oceanic region are substantial. The vertically integrated geographical distribution of pressure torque (figure $12 \mathrm{a} \& \mathrm{~b}$ ) 
depicts that the entire peninsular region is dominant of momentum destruction, which is balanced by the flux convergence over the domain. The pressure torque generates momentum along east Africa and adjoining Arabia, and contributes for destruction over the east Arabian Sea, Bay of Bengal, Burma and western Pacific. The pressure torque delineates maximum generation of momentum over the south Indian peninsular region. As explained earlier, during the monsoon season, strong momentum flux convergence is necessary to maintain the surface westerlies. The momentum generation/destruction due to pressure torque (east west pressure gradient) indicated by NCMRWF analysis is stronger compared to NCEP (figure 12c). The angular momentum budget terms connote that the intensity of monsoon circulation indicated by NCEP reanalysis is feeble. The large scale balances of vorticity and angular momentum adduce this aspect.

\section{Conclusions}

The study renders the following conclusions.

During the evolution phase of the monsoon, the vorticity balance is mostly governed by the transportation terms such as horizontal advections of relative and planetary vorticities and the vorticity generation due to stretching of isobars. However, during the established phase, the horizontal transportation of vorticity by the two advection terms exceeds the generation. In fact the amount of vorticity transported out of the monsoon domain is larger than the quantity generated by the stretching. This aspect connotes the generation of vorticity through some other means in order to provide the balance. Earlier studies asserted that the generation of vorticity due to sub-grid scale processes, also contributes towards the balance during the established phase of the monsoon. The present study expounded the balancing mechanism apart from differences during the evolution period. The horizontal advection of relative vorticity denotes positive advection in the lower as well as upper troposphere over the monsoon domain. In the middle troposphere the advection becomes minimum. The horizontal advection of planetary vorticity indicates same signature as that of meridional flow. The vorticity generation due to stretching depicts a maximum in the boundary layer and a minimum in the upper troposphere at jet level. The monsoon circulation is maintained by generation of cyclonic vorticity in the lower troposphere and anti-cyclonic vorticity in the upper troposphere. The mean circulation of the summer monsoon is characterized by a net vorticity advection from the region of its influence. This observation indicates that the monsoon area is quite unstable during the summer season with the production of vorticity within the domain itself in order to maintain the circulation. This production is manifested through subgrid scale processes such as cumulus convection, unlike other regions where the balance is between the transportation and stretching terms.

The angular momentum budget does not delineate any substantial difference during the evolution and established phases of the monsoon except in terms of strength. The angular momentum balance is basically maintained by the transportation terms such as flux divergences of omega and relative momenta and the generation term namely pressure torque over the monsoon domain. In this study, a net momentum flux convergence is observed over the region of low-level monsoon westerlies. Such a distribution is essential to maintain the low-level monsoon westerlies against the surface friction. It is also found that pressure torque contributes towards the production of momentum and balances the flux convergence over the summer monsoon region. Albeit, that the large scale balance requirements are fairly satisfied in both NCEP reanalysis and NCMRWF analysis, weak balances are noticed in NCEP reanalysis over the summer monsoon domain.

\section{Acknowledgements}

The authors express their gratitude towards the NCMRWF and NCEP for providing the data sets to carry out the present study. The authors are also thankful to the reviewers for their constructive comments, resulting in substantial improvement of the manuscript.

\section{References}

Anthes R A 1977 A cumulus parameterization scheme utilizing a one-dimensional cloud model; Mon. Weather Rev. $105270-286$

Campana K A, Hou Y T, Mitchell Yang S K and Cullather $\mathrm{R} 1994$ Improved diagnostic cloud parameterization in NMC's global model. Preprints 10th Conf. on Numerical Weather Prediction, Portland, OR; Amer. Meteor. Soc. 324-325

Chen S C, Norris C L and Roads J O 1996 Balancing the atmospheric hydrologic budget; J. Geophys. Res. 101 7341-7358

Chu J H, Yanai M and Sui C H 1981 Effects of cumulus convection on the vorticity field in the tropics Part-I: The large scale budget; J. Met.Soc. Japan 59 4, 535-546

Fein J S 1977 Global vorticity budget over the tropics and subtropics at $200 \mathrm{mb}$ during the northern hemisphere summer; Pageoph 115 1493-1500

Holopainen E O and Oort A H 1981 Mean surface stress curl over the oceans as determined from the vorticity budget of the atmosphere; J. Atmos. Sci 33 773-792 
Kalnay E and Co-authors 1996 The NCEP/NCAR 40-year reanalysis project; Bulletin of American Met. Society, $\mathbf{7 7}$ 3 437-471

Kanamitsu M 1989 Description of the NMC global data assimilation and forecast system; Weather Forecasting 4 $335-342$

Mo K C and Higgins R W 1996 Large scale atmospheric moisture transport as evaluated in the NCEP/NCAR and the NASA/DAO reanalyses; J. Climate 9 1531-1545

Mohanty U C and Ramesh K J 1994 A study on the dynamics and energetics of the Indian summer monsoon; Proceedings of the Indian National Science Academy, 60 A $1,23-55$

O'Brien J J 1970 Alternative solutions to classical vertical velocity problem; J. Appl. Met 9 197-203

Oort A H and Chan P H 1977 On the role of the Asian monsoon in the angular momentum and kinetic energy balances of the tropics; Pageoph, 115 1167-1186

Oort A H and Peixoto J P 1983 Global angular momentum and energy balance requirements from observations; $A d v$. Geophys 25 355-490

Pan H L and Mahrt L 1987 Interaction between soil hydrology and boundary layer development; Bound. Layer Meteor. 38, 185-220
Pan H L and Wan-Shu Wu 1994 Implementing a mass flux convective parameterization package for the NMC medium-range forecast model. Preprints 10th Conf. on Numerical Weather Prediction, Portland, OR; Amer. Meteor. Soc. 96-98

Parrish D F and Derber J C 1992 The National Meteorological Center's spectral statistical interpolation analysis system; Mon. Weather Rev. 120 1747-1763

Rao P L S 2001 The energetics of Asian summer monsoon; Pageoph 158 5-6 965-988

Reed R J and Johnson R H 1974 The vorticity budget of the synoptic-scale wave disturbances in the tropical western Pacific; J. Atmos. Sci. 31 17841790

Sardeshmukh P D and Held I M 1984 The vorticity balance in the tropical upper troposphere of a general circulation model; J. Atmos. Sci. 415 768-778

Schmitz J T and Mullen S L 1996 Water vapor transport associated with the summertime north American Monsoon as depicted by ECMWF Analyses; $J$ Climate 9 $1621-1634$

Slingo J M 1987 The development and verification of a cloud prediction scheme for the ECMWF model; Q.J.R. Meteorol. Soc. 113 899-927 